\title{
Liberalização financeira, performance econômica e estabilidade macroeconômica no Brasil: uma avaliação do período 1994-2007
}

\author{
Luiz Fernando de Paula \\ Professor da Faculdade de Ciências Econômicas \\ da Universidade do Estado do Rio de Janeiro \\ (FCE/UERJ) e pesquisador do CNPq \\ Manoel Carlos de Castro Pires \\ Pesquisador do Instituto de Pesquisa Econômica Aplicada (IPEA) \\ João Adelino de Faria \\ Pesquisador da UERJ/CNPq e mestre em \\ Economia pelo PPGCE/UERJ \\ Tiago Rinaldi Meyer \\ Doutorando pelo IE/UFRJ e analista da ELETROBRÁS
}

\section{Palauras-chave:}

liberalização da conta capital; crescimento econômico; economia brasileira

Classificação JEL E21, F32, F40.

\section{Key-words \\ liberalization of the capital account; economic growth; Brazilian economy.}

JEL Classification E21, F32, F40.

\section{Resumo}

Este artigo objetiva avaliar a relação entre liberalizaçáo da conta capital, performance econômica e estabilidade macroeconômica no Brasil. Para tanto, além de uma revisão da literatura, o artigo realiza uma avaliação empírica dos efeitos da liberalizaçáo financeira no Brasil sobre um conjunto de variáveis macroeconômicas com o uso da metodologia VAR, utilizando, para tanto, dois modelos: um com um indice de jure de liberalização financeira (ILF), e outro com um indice de facto de integração financeira (IIF). Procura-se, no primeiro caso, avaliar a hipótese de que a liberalização financeira resulta em redução no risco país e, consequentemente, na taxa de juros doméstica; no segundo caso, avaliase a hipótese de que a liberalização financeira tem impacto positivo sobre o crescimento econômico e a estabilidade macroeconômica vis-à-vis à hipótese dos críticos da liberalização financeira de que esta gera efeitos instabilizadores em países em desenvolvimento.

\section{Abstract:}

This paper aims to analyze the relationship between capital account liberalization, economic performance and macroeconomic stability in Brazil. For this purpose, besides a review of the literature, the paper makes an empirical study of the effects of financial liberalization in Brazil on a set of macroeconomic variables with the VAR methodology, using two models: one with a de jure index of financial liberalization (ILF) and another with a de facto index of financial integration (IIF). In the first model, the study intends to evaluate the proposal that financial liberalization results in a reduction of country-risk and, consequently, of the domestic interest rate. In the second case, it aims to assess the hypothesis that financial liberalization has a positive effect on economic growth and macroeconomic stability vis-à-vis the view of critics of financial liberalization that this generates unstable effects in developing economies. 


\section{1_Introdução}

Em função de inúmeras crises cambiais ocorridas na década de 1990 e no início desta década, vários estudos foram realizados para avaliar os efeitos da liberalização da conta capital sobre o crescimento econômico e a estabilidade macroeconômica. ${ }^{1}$ Os estudos, de modo geral, não têm encontrado resultados robustos na relação entre essas variáveis, conforme será reportado neste artigo. Assim, os supostos benefícios da liberalização financei$\mathrm{ra},{ }^{2}$ entendida como análoga ao processo de liberalização comercial, têm sido questionados. Aqueles que defendem o processo de liberalização financeira têm argumentado que tal processo ou deve ser feito de forma gradual e/ou a partir da existência de algumas precondiçóes, como um sistema financeiro desenvolvido e bem regulado, boa governança, políticas macroeconômicas consistentes, etc.

No Brasil, o processo de liberalização da conta capital vem ocorrendo desde o final dos anos 1980 e ainda há poucos estudos que avaliaram empiricamente a relação entre liberalização financeira e crescimento econômico no país. Estudos empíricos têm utilizado frequentemente índices de jure (normas referentes a controle de capitais), ao invés de índices de integração financeira (que medem o grau de integração aos fluxos de capi- tais). O debate acadêmico, em particular, foi centrado na proposta de plena conversibilidade da conta capital, feita originalmente por Pérsio Arida, em 2003, e que resultou em várias críticas subsequentes.

Este artigo objetiva avaliar empiricamente a relação entre liberalização financeira, performance econômica e estabilidade macroeconômica no Brasil. Para tanto, na seção 2 avalia-se a literatura internacional e nacional (teórica e empírica) sobre a temática; na seçâo 3, mostra-se resumidamente a evolução da legislação sobre controle de capitais no Brasil; na seção 4, examinam-se os índices de integração financeira (de jure e de facto) utilizados na literatura e aqueles que serão utilizados neste trabalho; na seção 5, realiza-se uma avaliação dos efeitos da liberalização financeira no Brasil sobre um conjunto de variáveis macroeconômicas com o uso da metodologia VAR, utilizando, para tanto, dois modelos: um com um indice de jure de liberalização financeira (ILF), e outro com um indice de facto de integração financeira (IIF). Procura-se, no primeiro caso, avaliar a hipótese de Arida de que a liberalização financeira resulta na redução do risco país e, consequentemente, na taxa de juros doméstica; no segundo caso, avalia-se a hipótese da literatura internacional pró-liberalização de que a li-
${ }^{1}$ Estabilidade

macroeconômica é aqui entendida numa dimensão ampla e não somente como estabilidade de preços, mas também como menor volatilidade do produto e menor propensão de uma economia a crises cambiais e a ataques especulativos à moeda.

${ }^{2}$ Neste artigo, utilizaremos os termos liberalização financeira, liberalização da conta capital e integração financeira internacional como sinônimos. 
beralização financeira tem impacto positivo sobre o crescimento econômico e a estabilidade macroeconômica, além de gerar efeitos disciplinadores sobre a política econômica, vis-à-vis à hipótese dos críticos da liberalização financeira de que esta gera efeitos instabilizadores em países em desenvolvimento. A seção 6 conclui o artigo.

\section{2_Literatura sobre liberalização financeira, performance econômica e estabilidade macroeconômica}

\section{1_Literatura internacional}

\subsection{1_ Argumentos favoráveis}

Os argumentos favoráveis à liberalização dos movimentos de capital tomam como base a teoria dos mercados eficientes, segundo a qual os preços refletem toda a informação disponível para os agentes econômicos, e estes fazem o melhor uso das informações disponíveis em suas previsóes dos preços futuros dos ativos; logo, os sinais de mercado provêm informações suficientes para a previsão dos eventos futuros, permitindo, assim, que os agentes formem suas expectativas racionais como base para as decisóes maximizadoras das funçôes utilidades
(SINGH, 2002). Assim, toda informação relevante sobre os "fundamentos econômicos” existe e está disponível aos participantes do mercado. Em particular, a eficiência ótima da alocação global de recursos resulta também do teorema de $\mathrm{He}$ cksher-Ohlin, segundo o qual a taxa de retorno dos fatores de produção de cada país depende da disponibilidade relativa dos fatores e, portanto, países com escassez de capital têm um rendimento real do investimento marginal maior que países desenvolvidos com abundância de capital. O livre fluxo de capitais, em mercados eficientes, permitiria a busca de retornos marginais maiores, reduzindo assim a escassez relativa de capital nos países em desenvolvimento. Portanto, a liberalização da conta capital é vista como um caminho inevitável para o desenvolvimento, uma vez que o movimento livre de capitais facilita a alocação global de poupanças e ajuda a canalizar recursos para usos mais produtivos, aumentando o crescimento econômico e o bem-estar (FISCHER, 1998; DORNBUSCH, 1998).

Prasad et al. (2003) resumem os potenciais benefícios da liberalização para países emergentes, os quais são relacionados:

a. ao maior acesso a mercados externos financeiros (provavelmente a custos menores de capital devido 
à melhor alocação de risco), aumentando a eficiência na alocação de poupanças no mundo e proporcionando melhores oportunidades para países dividirem o risco macroeconômico e assim suavizar o consumo; ${ }^{3}$

b. à pressão para um aprimoramento na supervisão financeira dos mercados financeiros domésticos;

c. ao maior acesso ao know-how tecnológico e ao conhecimento de outros países através do investimento direto estrangeiro (transferência de tecnologia);

d. ao desenvolvimento do setor financeiro devido aos efeitos da entrada de bancos estrangeiros sobre a oferta de crédito, estimulando melhores práticas bancárias, e também aos fluxos de capitais de portfólio que aumentam a liquidez nos mercados de capitais domésticos, permitindo o desenvolvimento destes;

e. à maior especialização da produção, levando ao aumento na produtividade, devido ao melhor gerenciamento de risco; f. à disciplina do mercado, que pode estimular políticas macroeconômicas consistentes, uma vez que a atuação dos investidores internacionais atua como uma força de mercado que penaliza as más políticas e recompensa as boas políticas.

Assim, para os economistas que defendem a liberalização da conta capital, esta é entendida como um passo inevitável para o caminho do desenvolvimento, que deve ser adotado para que as economias nacionais se beneficiem dos movimentos livres de capitais. Os benefícios da integração financeira internacional podem ser divididos em canais diretos, ou seja, aqueles que afetam diretamente o crescimento econômico, e canais indiretos, que afetam o crescimento de forma indireta, conforme a Figura 1.

\subsection{2_Avaliação crítica}

As críticas à liberalização financeira têm sido feitas principalmente por economistas de uma vertente mais keynesiana, seja novo-keynesiana (RODRIK, 1998; STIGLITZ, 2000), seja pós-keynesiana (DAVIDSON, 2002; KREGEL, 2008; PRIEWE, 2008). ${ }^{4}$

Tanto Stiglitz quanto Rodrik criticam a alocação ótima de recursos nos mercados financeiros em função da existência de assimetria de informaçóes, o que impede que a liberalização financei-

\footnotetext{
${ }^{3} \mathrm{O}$ argumento subjacente é que os fluxos de capitais externos evitam quedas profundas no consumo nacional durante a desaceleração cíclica - em caso de distúrbios cíclicos em termos de comércio, produto ou demanda externa - já que o consumo flutuaria menos do que a renda disponível, caso exista a possibilidade de conseguir empréstimos do resto do mundo durante os períodos de queda da renda.

${ }^{4}$ Para uma avaliação da abordagem convencional sobre liberalização financeira e de seus críticos, ver Damasceno (2007).
} 


\section{Figura 1 - Efeitos da integração financeira internacional}

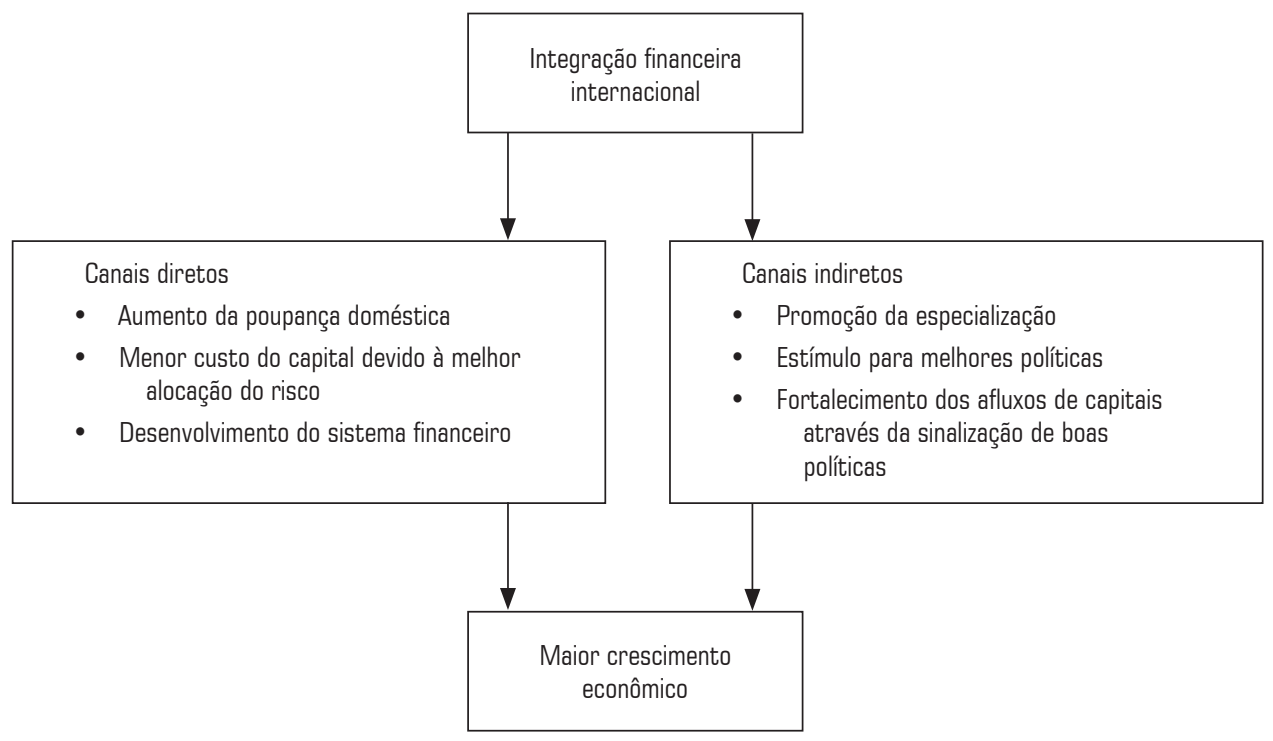

Fonte: Adaptado de Prasad et al. (2003, p. 24).

ra, seja doméstica ou internacional, resulte em melhoria no bem-estar. A existência de informação assimétrica gera custos de obtenção de informação e impede a eficiente precificação e alocação de recursos. Em suma, as falhas de mercado surgem da informação assimétrica, da "incompletude" de mercados contingentes e da racionalidade limitada (ou mesmo irracionalidade) que são endêmicas a mercados financeiros (RODRIK,
1998, p.4). Nesse sentido, fluxos de capitais seriam caracterizados por "manias e pânicos” (BHAGWATI, 1998, p. 8), sendo que "o paradigma de mercados eficientes é basicamente enganoso quando aplicado a fluxos de capitais" (EINCHENGREEN, 2004, p. 3). Stiglitz (2000) argumenta que economistas favoráveis à liberalização financeira sustentam que os ganhos desta seriam semelhantes aos ganhos obtidos no comércio de bens; contudo, 
mercados financeiros são diferentes dos mercados de bens e serviços, por conta da existência de informação imperfeita (ver, também, BHAGWATI, 1998). O autor critica também o argumento de que a integraçáo financeira internacional promove maior estabilidade macroeconômica, já que a mesma está associada a maior instabilidade, pelo fato de os fluxos de capitais serem marcadamente pró-cíclicos, exacerbando as flutuaçóes econômicas, quando não as causando, e expondo os países às vicissitudes associadas a mudanças nas circunstâncias econômicas de fora do país. ${ }^{5}$ Assim, Stiglitz (2000) sustenta que a integração financeira internacional desestimula o investimento e crescimento econômico, uma vez que a liberalização financeira, por um lado, facilita a fuga de capitais do país, com efeitos adversos sobre o crescimento econômico, e, de outro, resulta na presença do risco de instabilidade que acaba por desencorajar as decisóes de investimento.

Pós-keynesianos também rejeitam a hipótese dos mercados eficientes e das expectativas racionais para explicar o comportamento dos mercados financeiros (GLICKMAN, 1994; EATWELL e TAYLOR, 2000; DAVIDSON, 2002, cap.11). Em um mundo caracterizado pela incerteza, em que os fundamentos não fornecem um guia confiável sobre o futuro, uma vez que a base informacional sobre a qual se apoiam as decisóes humanas sobre acumulação de riqueza é incompleta, as avaliaçôes futuras dos mercados são sempre sujeitas a desapontamentos. Nessa perspectiva, o "valor intrínseco" ou "fundamental" dos preços dos ativos não é passível de cálculo num ambiente caracterizado pela incerteza radical (não-probabilística), já que a taxa de desconto varia de acordo com as percepçóes de risco que se alteram em respostas a eventos e, por isso, não são passíveis de conhecimento. Assim, práticas especulativas de curto prazo e não os fundamentos de longo prazo determinam os preços dos ativos. Nesse contexto, a integração financeira internacional tem sido fonte de instabilidade ampliada no que se refere à ocorrência de crises cambiais e ataques especulativos e à diminuição no grau de liberdade de políticas econômicas domésticas, com efeitos profundos sobre as variáveis reais da economia (produto e emprego). Especulação, uma atividade de antecipação da psicologia do mercado, em uma economia global, tem caráter disruptivo não somente em mercados domésticos, mas sobre países como um todo, criando uma espécie de cassino financeiro ampliado (ALVES JUNIOR et al., 1999-2000). Em particular, sob condiçóes de mobilidade de capitais, a taxa de câmbio passa cada vez mais

\footnotetext{
${ }^{5}$ Resende e Amado (2007), utilizando um referencial teórico minskiano, mostram evidências empíricas de que os ciclos de crescimento nos principais países da América Latina (Argentina, Brasil e México) se comportam de modo reflexo aos ciclos de liquidez internacional, indo ao encontro do argumento de pró-ciclidade dos fluxos de capitais de Stiglitz. Para uma análise da relação entre liberalização financeira, crescimento econômico e crises financeiras em uma perspectiva keynesiana, ver Cunha (2004).
} 
${ }^{6}$ Para uma definição mais precisa dos índices de liberalização financeira, ver a seção 4 .

${ }^{7}$ Segundo Eichengreen e Leblang (2002) é difícil de acordo com as evidências da literatura empírica identificar um efeito robusto da liberalização da conta capital sobre o crescimento, uma vez que tais estimativas são sensíveis ao tipo de amostra e às especificações da pesquisa. a ser determinada pelas decisóes de portfólio dos investidores internacionais. Assim, fluxos de capitais passam a ter uma forte influência sobre os mercados cambiais, tornando as taxas de câmbio bem mais voláteis do que seriam se seus movimentos fossem explicados pelo comportamento dos fluxos de comércio e de serviços produtivos. As decisões de portfólio, por sua vez, são dependentes das mudanças nos sentimentos de mercado, isto é, das expectativas formuladas pelos investidores, sendo tais expectativas "modeladas" usando uma combinação entre comportamentos convencionais - como a convenção de que os agentes consideram a opinião média quando formam suas expectativas frente a um futuro incerto - e de outros fatores de natureza psicológica (HARVEY, 2003).

Concluindo, do exposto fica claro que, nas duas vertentes keynesianas, o processo de liberalização da conta capital, em que pesem os benefícios reais da integração financeira, tem efeito instabilizador sobre economias emergentes, tornando os países mais propensos a reversóes cíclicas, resultando em efeitos duvidosos sobre o crescimento econômico.

\subsection{3_ Estudos empíricos}

Vários estudos empíricos - normalmente utilizando dados em painel e medindo a integração financeira internacional através de índices variados, de jure e de facto ${ }^{6}$ - procuraram avaliar a relação entre liberalização de conta capital, por um lado, e crescimento econômico, crises econômicas e/ou volatilidade macroeconômica, de outro. Evidentemente essas três últimas variáveis estão relacionadas, no sentido de que crises econômicas e volatilidade macroeconômica impactam sobre crescimento econômico.

Algumas resenhas feitas sobre o assunto revelam que as evidências empíricas, em geral, não mostram uma relação robusta entre liberalização financeira e crescimento econômico (EINCHENGREEN, 2004, cap. 3). Prasad et al. (2003, p. 32), do Fundo Monetário Internacional (FMI), reportam 14 estudos feitos entre 1992 e 2002 sobre a relação entre integração financeira e crescimento econômico e mostram que apenas três estudos encontram um efeito positivo, enquanto quatro não encontram nenhum efeito e os outros sete apresentam um efeito misto. ${ }^{7}$ Rodrik (1998, p. 61) avaliou tal relação no período 1977-1989 em quase 100 países, com o uso de algumas variáveis de controle (como matrículas em ensino secundário no início do período), e concluiu que "os dados não oferecem nenhuma evidência de que países em desenvolvimento sem controle de capitais 
tenham crescido mais rápido, investido mais, ou experimentado inflação menor. Controles de capitais são essencialmente não correlacionados com o desempenho econômico no longo prazo, uma vez que controlemos outros determinantes”. Quinn (1997), utilizando um índice gradativo para avaliar o grau de abertura financeira numa escala de 0 a 8 , com base em informações do relatório AREAER (The Annual Report on Exchange Arrangements and Exchange Restrictions) do FMI para um conjunto amplo de 64 países no período 1890-1989, é um dos primeiros a apresentar um efeito positivo robusto entre liberalização e crescimento da renda per capita. Contudo, como assinalam Edison et al. (2002), os resultados de Quinn são dominados pelo que ocorreu com os países da Organização para a Cooperação de Desenvolvimento Econômico (OCDE).

Prasad et al. (2003, p. 6) sintetizam os achados empíricos obtidos nos estudos realizados, concluindo que "um estudo sistemático das evidências sugere que é difícil estabelecer uma relação causal robusta entre integração financeira [e crescimento econômico]", além de sugerirem que as crises externas da década de 1990 podem ter aumentado a volatilidade macroeconômica dos países em desenvolvimento, como eviden- ciado pelo aumento na volatilidade do consumo por parte dos países emergentes financeiramente integrados. Esse resultado é corroborado por Kose et al. (2006), que confirmam o aumento na volatilidade do consumo nos anos 1990 em países que possuem amplos fluxos financeiros e mostram que há pouca evidência de que os países em desenvolvimento se beneficiaram de maior integração financeira para estabilizar as flutuações de consumo.

Alguns estudos apresentam resultados que podem elucidar certas questóes na relação entre liberalização da conta capital e crescimento econômico. Eichengreen e Leblang (2002), por exemplo, sugerem que países desenvolvidos primeiro expandiram seus mercados financeiros domésticos, ao que se seguiu uma conversibilidade restrita da conta capital, para só entâo a liberalizarem: "o impacto da liberalização da conta capital é mais provável ser positivo quando os mercados financeiros domésticos são bem desenvolvidos e regulados e a operação do sistema financeiro internacional é suave e estável. É mais provável ser negativo quando os mercados financeiros, doméstico e internacional, estão sujeitos à crise" (Eichengreen e Leblang, 2002, p. 2, itálicos acrescentados). Edwards (2001), por outro lado, ao avaliar a hipótese de que a liberaliza- 
ção da conta capital gera efeitos distintos em países de alta e baixa renda, no período de 1973 a 1988, utilizando uma medida de intensidade de restrições da conta capital, encontra que a liberalização financeira estimulou o crescimento econômico dos países de alta renda nos anos 1980, mas reduziu o crescimento no caso dos países de baixa renda. ${ }^{8} \mathrm{Na}$ mesma direção, ao desagregarem sua análise empírica em subgrupos de países, Eichengreen et al. (2009) encontram que o efeito positivo da abertura financeira sobre o crescimento de indústrias dependentes de financiamento externo é obtido principalmente em países de mais alta renda, e, ainda, que os efeitos positivos da liberalização são limitados a países com sistemas financeiros bem desenvolvidos, padrões contábeis bons e fortes direitos do credor.

Três lições podem ser extraídas desses achados. Primeiro, que a conver- sibilidade da conta capital, se precipitada, pode comprometer o desenvolvimento do sistema financeiro doméstico de um país em desenvolvimento, em função justamente da maior instabilidade macroeconômica gerada pela volatilidade nos fluxos de capitais externos. Assim, o desenvolvimento do sistema financeiro doméstico parece ser na realidade uma precondição para a liberalização financeira. Segundo, e relacionado ao anterior, que países desenvolvidos liberalizaram sua conta capital apenas após atingirem o estágio de economias maduras. Terceiro, e relacionado ao anterior, que os países devem alcançar alguns patamares mínimos (thresholds) em termos de desenvolvimento econômico e institucional antes de obterem os benefícios da liberalização financeira. ${ }^{9}$ A crítica que se faz a esta abordagem é que tais patamares referem-se, justamente, aos mesmos fatores que haviam

\footnotetext{
${ }^{8}$ Contudo, uma pesquisa feita por Henry (2007) argumenta que a maioria dos estudos que buscam testar o efeito da liberalização da conta capital sobre o crescimento econômico, ao procurarem uma relação robusta de longo prazo, de certa maneira se
}

equivocam, uma vez que o que o modelo neoclássico (baseado na teoria da eficiência alocativa) prediz é que a liberalização financeira em países pobres de capital aumenta temporariamente (e não permanentemente) a taxa de crescimento da renda per

\author{
capita, sendo tal relação forte e \\ estatisticamente significativa. \\ ${ }^{9}$ Nesse sentido, um estudo \\ do FMI (KOSE et al., 2006) \\ sugere que, para os países \\ em desenvolvimento \\ tirarem proveito da \\ liberalizaçáo da conta \\ capital, seria necessário que \\ determinados pré-requisitos \\ ou patamares mínimos já \\ tivessem sido atingidos, \\ como desenvolvimento do \\ mercado financeiro, qualidade \\ institucional, governança das \\ políticas macroeconômicas \\ e integração comercial; \\ do contrário, a abertura \\ financeira resultaria em \\ ampliação de riscos.
}


sido apontados por esses mesmos autores como benefícios colaterais, gerando uma contradição lógica entre consequências e pré-requisitos (PRIEWE, 2008).

\section{2_2 Literatura nacional}

\subsection{1_Argumentos pró e contra \\ a conversibilidade do real}

A discussão sobre a liberalização da conta capital no Brasil teve com um dos eixos principais a avaliação da proposta de Pérsio Arida de plena conversibilidade do real. A hipótese central de Arida (2003a; 2003b) é que a manutenção de controles administrativos nas transaçóes com moeda estrangeira conduz à situação na qual as taxas de juros interna e externa no Brasil sejam mais altas que as que prevaleceriam numa situação de plena conversibilidade. A adoção da conversibilidade livre afirmaria em alto e bom tom a confiança do Banco Central do Brasil (BCB) em sua política, isto é, o $\mathrm{BCB}$ emitiria um claro sinal de que tem tanta confiança no sucesso da política econômica que permitiria que se comprassem divisas, o quanto se quisesse, à taxa de câmbio vigente, uma vez que sempre haveria reservas suficientes. A eliminação dos controles administrativos nas transações com mo- eda estrangeira - com a introdução de um regime de livre conversibilidade nas transações no mercado de câmbio - seria para Arida uma estratégia complementar à obtenção dos elevados superávits primários na tarefa de redução do endividamento público como proporção do Produto Interno Bruto (PIB), na medida em que taxas de juros internas e externas mais baixas permitiriam: (i) um superávit primário mais baixo, e (ii) um nível de investimento mais alto por parte das empresas domésticas e, portanto, um maior crescimento econômico.

O eixo central de sua argumentação é, portanto, que as restriçóes administrativas às transaçóes com moeda estrangeira aumentam as taxas de juros interna e externa devido ao efeito que têm sobre o prêmio de risco, o que acaba gerando a necessidade de superávits primários ainda maiores. Em outras palavras, o prêmio de risco depende, entre outros fatores, do regime de conversibilidade da moeda doméstica. ${ }^{10}$ Os efeitos da conversibilidade restrita sobre as taxas reais de juros ocorrem de duas formas interdependentes: (i) efeito sobre o prêmio de risco externo: a manutenção de um regime de conversibilidade restrita sinaliza para os credores externos a possibilidade de o BCB suspender ou contin-
10 “...] surge, aos olhos do credor em moeda estrangeira, um risco desnecessário. Quem empresta seus dólares a residentes no Brasil sabe que está correndo o risco de o devedor não ser capaz de gerar os reais necessários para quitar a dívida à taxa de câmbio vigente quando do seu vencimento. A este risco de crédito, soma-se entâo outro, o risco da espada de Dâmocles do Banco Central ser posta em uso, suspendendo-se, seletiva ou generalizadamente, os pagamentos ao exterior e criando-se um racionamento de divisas por via administrativa. Cresce, por conseguinte, a taxa de juros em dólares requerida pelo credor e com ela a taxa de juros em reais" (ARIDA, 2003b, p. 153). 
${ }^{11}$ Para uma crítica de natureza teórica à conversibilidade plena da conta capital, destacando o papel da preferência pela liquidez na instabilidade econômica, ver Mollo e Amado (2006).

${ }^{12}$ Os estudos empíricos que avaliam a hipótese de Arida serão reportados na próxima seção. genciar os pagamentos ao exterior no futuro. Dessa forma, o risco de default dos compromissos externos das empresas domésticas aumenta, gerando uma elevação da taxa de juros off-shore; (ii) efeito sobre o prêmio de risco interno: sendo válida a "paridade descoberta da taxa de juros", a taxa de juros nominal doméstica deve ser igual à soma da taxa de juros internacional com o risco país e a expectativa da desvalorização cambial. Portanto, pelo efeito acima referido, haveria um aumento no risco país e/ou uma expectativa de depreciação excessiva da moeda doméstica devido ao risco de imposição de restrições à liberdade de capitais, o que resultaria em patamares mais elevados das taxas reais de juros domésticas. Assim, a manutenção de um regime de conversibilidade restrita sinalizaria para os credores internos a pouca confiança que o próprio Tesouro tem na sua capacidade de honrar os compromissos financeiros devidos à dívida interna. Essa sinalização tem o efeito de aumentar o prêmio de risco sobre os títulos da dívida doméstica, o que conduz a uma elevação da taxa de juros interna.

Em artigo posterior, Arida (2004) acrescenta novos argumentos em favor da conversibilidade plena da conta capital no Brasil. Em primeiro lugar, a abertura da conta capital, quando empreendida no bojo de políticas macroeconômicas sólidas e sustentáveis, traz ganhos de bemestar, em função dos seus efeitos na melhor alocação internacional do capital e da diminuição do impacto das flutuaçóes da renda sobre o consumo, argumentos já desenvolvidos na literatura internacional. Em segundo lugar, em regimes de câmbio flutuante a possibilidade de introdução de controles agrava os desajustes no mercado cambial. A eliminação do risco de conversibilidade, por sua vez, permitiria uma maior estabilização dos fluxos de entrada e saída de capitais, reduzindo a amplitude da flutuação cambial. Segundo Arida, a faculdade do BCB de impor controles de câmbio afeta a "auto-equilibração" do mercado cambial e, nessa medida, impede que os excessos sejam corrigidos pelo próprio mercado. Sob câmbio flutuante, o processo de "auto-equilibração" dos fluxos de capitais ocorre naturalmente, sem interferência do BCB.

Críticos da proposta de Arida (BELUZZO e CARNEIRO, 2004; OREIRO et al., 2004; FERRARI FILHO et al., 2005) ${ }^{11}$ sustentam que o argumento de que as restriçóes administrativas às transaçóes com moeda estrangeira aumentam as taxas de juros interna e externa, devido ao efeito das mesmas sobre o prêmio de risco país, não tem respaldo empírico. ${ }^{12} \mathrm{De}$ fato, a experiência histórica brasileira te- 
ria mostrado precisamente o contrário: ao longo dos anos 1990, o Brasil caminhou na direção de uma conversibilidade crescente da conta capital, sem que houvesse uma tendência de redução no risco país ou na taxa real de juros doméstica. Em segundo lugar, tal como assinalado na seção 2.1, quanto aos aludidos ganhos de bem-estar derivados da abertura da conta capital quando empreendida no contexto de políticas macroeconômicas "sólidas", a literatura empírica internacional mostra que a relaçáo entre os efeitos da liberalização financeira e o crescimento econômico não tem sido conclusiva. Em terceiro lugar, além de questionarem a capacidade autorreguladora do mercado cambial, os críticos argumentam que a excessiva volatilidade da taxa de câmbio tem efeitos deletérios sobre as decisóes de investimento e, consequentemente, sobre o crescimento econômico.

\subsection{2_Estudos empíricos}

Oreiro et al. (2004) realizam o primeiro estudo a avaliar a hipótese de plena conversibilidade do real de Arida, utilizando uma regressão com método dos mínimos quadrados com dados mensais no período 1994-2000, tendo como variáveis a dívida pública/PIB, a variação do risco país (JP Morgan) e dois índices de controles de capitais. Os resultados mostram que a conversibilidade da conta capital, tal como medida pelo índice de controle de capitais de Cardoso e Goldfajn (1998), tem efeito estatístico irrelevante sobre o prêmio de risco país, ou seja, não há uma relação direta estabelecida entre mudanças nos controles administrativos em relação à conversibilidade da moeda nacional e a variação do prêmio de risco país.

Ono et al. (2005), com o objetivo de avaliar a validade empírica dos argumentos de Arida em favor da plena conversibilidade do real, realizaram testes econométricos a fim de captar as possíveis implicações dos regimes da conta capital sobre o desempenho macroeconômico no período 1990-2001. Utilizando a metodologia VAR, analisaram a influência da liberalização financeira, medida por meio do índice de controle de capitais (ICC), sobre as seguintes variáveis macroeconômicas: taxa de juros (Selic) e taxa nominal de câmbio. Realizaram, também, outro teste econométrico utilizando dados em painel para analisar a relação da conversibilidade da conta capital com o desempenho macroeconômico para um conjunto de 87 países, valendo-se das variáveis PIB per capita, taxa de alfabetização, expectativa de vida, taxa de investimento, consumo do governo e taxa de poupança. Os resultados obtidos nos dois testes realiza- 
dos rejeitam a tese defendida por Arida e outros autores de que os controles de capitais poderiam atuar no sentido de desajustar o mercado cambial, aumentar a taxa de juros e comprometer a performance macroeconômica. Ao contrário, os resultados mostraram que os controles de capitais podem atenuar a volatilidade da taxa de câmbio e reduzir a taxa de juros.

Goldfajn e Minella (2005) analisaram a relação entre liberalização da conta de capital e volatilidade macroeconômica no Brasil no período recente. No que se refere à suavizaçáo do consumo e à redução na volatilidade da taxa de crescimento do PIB, os autores mostram evidências de que ambas as variáveis têm tido um comportamento mais estável, de acordo com o comportamento do desvio padrão, no período recente (1992-2003), comparativamente às décadas de 1970 e 1980. Ademais, por meio da metodologia VAR eles analisaram, para o período de janeiro de 1995 a agosto de 2004, a relação entre fluxos de capitais e desempenho econômico, procurando aferir o impacto dos movimentos dos fluxos de capitais sobre um conjunto de variáveis econômicas: produção industrial, saldo de transaçóes correntes, conta capital privado, termos de troca (medido como uma razão dos preços de exportaçóes sobre os preços das importaçóes), EMBI+ Brasil, taxa de câmbio real efetiva e taxa de juros real doméstica (taxa Selic). Os resultados das funçôes impulso resposta e da decomposição da variância mostram que um aumento no risco país gera uma resposta positiva na taxa de juros, uma depreciação na taxa de câmbio, uma redução nos fluxos de capitais e, após algum $l a g$, uma queda no produto. Por outro lado, choques positivos para fluxos de capitais não são persistentes, embora acarretem uma redução na taxa de juros, que, por sua vez, parece causar uma depreciação na taxa de câmbio. Os autores interpretam tais resultados como uma indicação de que a liberalização financeira tem conduzido a uma redução da vulnerabilidade externa e à volatilidade macroeconômica do país, possivelmente entendendo que a combinação entre regime de câmbio flutuante e abertura da conta capital tem efeito disciplinador sobre a política econômica, com efeitos benéficos sobre os fundamentos econômicos (risco país) e sobre a volatilidade macroeconômica.

Vaan der Laan (2007) avaliou o processo de liberalização da conta capital para um período compreendido entre 1990 e 2005. Para isso, utilizou dois índices: um indice de jure, índice de controle de capitais (ICC), e outro indice de facto, índice 
de abertura financeira (IAF). Fazendo uso da metodologia VAR realizou uma análise econométrica (com dados trimestrais no período de 1994-2005) para testar a relação causal positiva entre a liberalização financeira e o crescimento econômico, utilizando, para tanto, as seguintes variáveis macroeconômicas: taxa de juros Selic, taxa de câmbio nominal e variaçóes do PIB (a preço de mercado). Os resultados obtidos não permitiram estabelecer uma relação positiva e robusta entre liberalizaçáo financeira (tanto de jure quanto de facto) e crescimento econômico para o período analisado. Outros resultados importantes obtidos foram: o ICC é pouco significativo para explicar o comportamento da taxa de juros, sendo ainda praticamente independente dos resultados do câmbio, o que leva o autor a questionar os efeitos benéficos da liberalização de jure defendida por Arida (redução na taxa de juros e na volatilidade cambial, com efeitos benéficos sobre o crescimento); quanto ao IAF, seu comportamento gera fortes efeitos oscilatórios sobre as variaçóes na taxa de câmbio (mas sem tendência definida) e seu aumento tende a elevar o nível da taxa de juros praticada no país. O autor conclui que o aumento da liberalização da conta capital no Brasil tem um efeito líquido negativo, ainda que limitado.

Nota-se que a maioria dos traba- lhos no Brasil utilizou o índice de controle de capitais, elaborado por Cardoso e Goldfajn (1998). Em parte, o motivo deriva do fato de que boa parcela dos estudos visou avaliar a hipótese de conversibilidade plena do real feita por Arida. Dos quatro trabalhos empíricos reportados, três mostraram evidências de que a liberalização financeira não teve resultados robustos sobre o crescimento econômico e/ou variáveis relacionadas a este, e apenas um mostra resultados benéficos relacionados à redução da volatilidade macroeconômica.

\section{3_Legislação sobre controle de capitais no Brasil}

A legislação cambial que, grosso modo, vigorou até início dos anos 1990, restringia a mobilidade de capitais no Brasil tendo três pilares básicos (VAN DER LAAN, 2007, cap. 2). Em primeiro lugar, dois decretos da década de 1930 (Decreto 20.451/31 e Decreto 23.258/33) estabeleceram o monopólio do Banco do Brasil na compra de divisas cambiais (em 1964 transferido ao Banco Central do Brasil - BCB), conferindo a este a possibilidade de utilizar o mecanismo de centralização cambial em períodos de crise e a base legal da exigência de cobertura cambial das exportaçóes (exportado- 
${ }^{13}$ Conta criada nos anos 1960 para permitir que não residentes recebessem depósitos em conta corrente mantida em um banco brasileiro, convertendo dólares em moeda doméstica. Somente o saldo residual da conta poderia ser reenviado para o exterior.

${ }^{14} \mathrm{O}$ Imposto sobre Operaçôes Financeiras (IOF) era, em outubro de 1994 , de $5 \%$ a $9 \%$ para aplicaçóes direcionadas aos Fundos de Renda Fixa Capital Externo (FRFCE), e de $3 \%$ a $7 \%$ no caso de aporte sob a forma de empréstimo. res ficam obrigados a vender moeda estrangeira auferida em suas transações ao BCB). Em segundo lugar, a Lei 4.131/62 estabeleceu que somente poderiam retornar ao exterior capitais que, ao ingressarem no país, houvessem sido registrados no BCB. Assim, a repatriação de capital era limitada ao valor do ingresso original acrescido dos juros pactuados e remuneração do capital. Essa seria a base da não conversibilidade da conta capital, restringir residentes de enviarem recursos para o exterior. Em terceiro lugar, pelo mecanismo conhecido como "posição de câmbio", através de normativas editadas pela autoridade monetária, havia limites às instituições para as posições comprada e vendida de câmbio, o que configurava, na prática, restrições quantitativas.

Desde o final da década de 1980 houve uma tendência crescente de liberalização da conta capital no Brasil. Já no começo dos anos 1990, as proibiçóes e entraves burocráticos que impediam investimentos diretos estrangeiros (IDE) foram eliminados. Em 1991, foi permitido aos investidores institucionais estrangeiros negociar títulos e açóes emitidos domesticamente, através do então chamado Anexo IV. Em 1992, o BCB autorizou uma ampla liberalização em relação à saída de capital, permitindo que uma conta especial não residente, cha- mada CC $5,{ }^{13}$ pudesse ser operada com mais liberdade por instituiçóes financeiras estrangeiras na compra e venda de divisas. Essa exceção criou um caminho fácil para a saída de capital de curto prazo, que foi bastante usado durante períodos de ataque especulativo contra a moeda nacional e que representou a introdução de uma conversibilidade de facto, já que, na prática, residentes podiam fazer depósitos em uma conta de um banco estrangeiro, operada em um banco no país, que poderia converter moeda nacional em moeda estrangeira (GOLDFAJN e MINELLA, 2005). Em abril de 1994, o Plano Brady converteu os empréstimos estrangeiros em títulos da dívida, ajudando a superar a crise da dívida externa que marcou os anos 1980. Ainda em 1994, o BCB implementou temporariamente um imposto (IOF) sobre a entrada de capitais ${ }^{14}$ e aumentou os requisitos mínimos de maturidade para a entrada de capital no país, visando amenizar a pressão sobre a taxa de câmbio, minimizar o custo de esterilização e proporcionar algum grau de liberdade para a política monetária, em um contexto de câmbio semifixo.

Após a crise de 1999 e a adoção do regime de câmbio flutuante, as autoridades econômicas implementaram uma série de normas cambiais que resultou na 
consolidação e no aprofundamento das mudanças efetuadas na década de 1990, permitindo a redução nas restrições operacionais e exigências burocráticas, assim como uma maior flexibilidade no mercado cambial. Tais medidas incluíram, na década de 2000, a unificação dos mercados existentes (livre e flutuante), a redução e posterior eliminação tanto da necessidade de maturidade mínima para empréstimos externos quanto do imposto sobre entrada de capitais, a eliminação das restrições para investimentos no mercado de títulos por parte de investidores estrangeiros e, ainda, a simplificação dos procedimentos relacionados à remessa de capital para outros países. ${ }^{15}$ Em agosto de 2006, o governo brasileiro introduziu mais flexibilidade nas operaçóes de cobertura cambial para exportação, passando a permitir que exportadores brasileiros mantivessem, fora do país, até 30\% das suas receitas com exportação, sendo que em março de 2008 estipulou que os exportadores brasileiros poderiam manter tais receitas em até 100\% no exterior. Ainda em março de 2008, de modo a arrefecer a entrada de capitais especulativos no Brasil, foi instituída uma alíquota de IOF de 1,5\% sobre a entra$\mathrm{da}$ de recursos estrangeiros dirigidos para renda fixa, que acabou tendo pouco efeito sobre os fluxos de capitais.

\section{4_Índices de \\ liberalização/integração financeira}

O processo de liberalização financeira de economias nacionais pode ser avaliado de duas formas distintas, quais sejam: a integração avaliada como resultado de um conjunto de normas que permite ou restringe a livre entrada e saída de capitais financeiros, e a integração vista como resultado da intensidade de entrada e saída de capitais financeiros. Para o primeiro caso, são utilizados indicadores que buscam mensurar o grau de abertura financeira permitido pela legislação em vigor em determinada economia. Esses índices são comumente chamados de indices de jure. Os índices de jure, assim, mensuram o grau de abertura financeira por meio de uma análise criteriosa da legislação e de suas alteraçóes. Para o segundo caso, são utilizados indicadores que buscam avaliar a intensidade dos fluxos de capitais em uma determinada economia. Esses índices são comumente chamados de indices de facto.

$\mathrm{Na}$ literatura existem formas diferentes de construção do indice de jure. Um modo comum é a utilização do relatório Annual Report on Exchange Arrangements and Exchange Restrictions (AREAER), publicado pelo FMI, no qual são listados os instrumentos utilizados em

\footnotetext{
${ }^{15}$ Em março de 2005, o $\mathrm{BCB}$ autorizou indivíduos e empresas a realizarem transferências de recursos para o exterior pelas suas próprias contas correntes, uma simplificação que acabou levando ao fim da conta CC5. Para um aprofundamento das normas cambiais na década de 2000, ver Paula (2011, cap. 4).
} 
${ }^{16}$ Esse índice, embora bastante utilizado, tem a limitação de não dar conta do grau de eficácia das normas implementadas, ou seja, algumas normas podem ser mais abrangentes que outras. cada um dos países membros. Essa lista de instrumentos é utilizada para categorizar a legislação do país em determinado ano como restritiva ou liberal, o que possibilita a construção de um indicador binário. Outra forma de construção de indice de jure é o Índice de Controle de Capitais (ICC) proposto por Cardoso e Goldfajn (1998). Duas medidas de controle de capitais $\left(\Delta C C_{1}\right)$ e $\left(\Delta C C_{2}\right)$ são definidas como combinaçóes lineares de mudanças nas restrições sobre fluxos de saída e fluxos de entrada de capitais, buscando medir o controle sobre os fluxos de capitais, baseando-se em alteraçóes na legislação. Uma mudança na legislação que venha a reduzir o fluxo de capitais recebe valor igual $\mathrm{a}+1$, enquanto uma mudança na legislação direcionada para estimular o fluxo de capitais recebe valor igual a -1 . Assim, temos que $\Delta C C_{1}=\Delta R I-0,5 . \Delta R O$ (1) e $\Delta C C_{2}=\Delta R I+0,5 . \Delta R O$ (2), onde $\Delta R I$ é uma medida imposta sobre o fluxo de entrada de capitais e $\Delta R O$ é uma medida que capta a variaçáo da norma sobre a saída de capitais. ${ }^{16}$

Van der Laan (2006), em sua pesquisa empírica, utilizou este Índice de Controle de Capitais (ICC) sem ponderação e, inversamente ao ICC original, estabeleceu que, se a alteração facilita a entrada e/ou a saída de capitais, atribui-se um valor +1 , ou seja, o controle foi reduzido.
Se, por outro lado, a alteração dificulta a entrada e/ou a saída de capitais, atribui-se um valor -1, ou seja, os controles são aumentados. Dessa forma, conforme as alterações na legislação ocorrem, se o valor do índice (ICC) se torna mais positivo é porque houve uma redução no controle sobre os fluxos de capitais, e vice-versa. Outra forma de construção do indice de jure buscando melhorar a mensuração do processo de liberalização normativa é o índice elaborado originalmente por Quinn (1997), que qualificou as alteraçóes na legislação sobre controle de capitais como " $-1,-2,-3,-4$ " ou " $+1,+2,+3,+4$ ", conforme a alteração seja mais ou menos liberalizante ou restritiva, respectivamente. A medida de Quinn é uma medida qualitativa, mas que tem sido criticada por seu caráter subjetivo. Chinn e Ito (2006), por sua vez, desenvolveram um índice de abertura financeira baseado nos componentes principais extraídos da conta capital desagregada e de medidas de restrição na conta corrente, a partir do AREAER.

Os indices de jure, em geral, são criticados como medida de integração financeira por nem sempre refletirem o real grau de integração financeira de uma economia nos mercados mundiais. Exemplo disso é a integração financeira da China, que a despeito do alto grau de restrição existente na legislação sobre vá- 
rias modalidades de capital (em particular, de residente), tem recebido altos volumes de influxos de capitais. De qualquer modo, tais índices mostram uma dimensão importante do processo de integração financeira internacional: em que medida as normas regulatórias têm sentido liberalizante ou sentido restritivo. Essa crítica nos remete ao indice de facto.

Os indices de facto mensuram a integração financeira por meio da razão entre os fluxos de capitais e um indicador do tamanho da economia nacional, geralmente o produto nacional. Kray (1998) e van der Laan (2007) utilizaram a soma dos fluxos financeiros de entradas e saídas sobre o PIB (em módulo), em uma analogia ao indicador de abertura comercial (exportaçóes mais importaçôes sobre o PIB), para construir o índice de integração de facto - intitulado Índice de Abertura Financeira (IAF). Lane e Milesi-Ferretti $(2003,2006)$ sugerem a construção de uma medida de integração financeira internacional (IFIGDP) que é a soma dos estoques de ativos e de passivos externos divididos pelo GDP, em que onde $F A(F L)$ denotam os estoques de ati-

$$
I F I G D P_{i t}=\frac{\left(F A_{i t}+F L_{i t}\right)}{G D P_{i t}}
$$

vos (passivos) externos. Esse índice, portanto, considera ativos e passivos, incluin- do tanto a habilidade dos estrangeiros em investirem num país quanto a habilidade de residentes em investirem no exterior e, por isso, é entendido como adequado para aferir o grau de integração financeira internacional de um país, uma vez que procura refletir o grau de integração financeira internacional deste país. ${ }^{17}$

Neste trabalho, foi utilizado como indice de jure os dados do índice construído por van der Laan (2007), com os dados primários deste sendo atualizados pelos autores para o período compreendido entre o terceiro trimestre de 2005 e o quarto trimestre de 2007. Renomeamos o índice como Índice de Liberalização Financeira (ILF), atribuindo o valor +1 para uma alteração na legislação que facilita a entrada e/ou a saída de capitais e o valor -1 para uma alteração na legislação que as dificulta. Dessa forma, quando o indicador está se tornando mais positivo é porque está havendo um movimento de liberalização financeira na legislação. Apesar de seu problema qualitativo (ver nota 16), a evolução deste índice mostrada na Figura 2 é bastante aderente à evolução das normas cambiais no Brasil, tal como foi apresentado resumidamente na seção $3 \mathrm{e}$ com mais detalhes em outros trabalhos. ${ }^{18}$

Como indice de facto foi utilizado neste trabalho o Índice de Integração Financeira (IIF), seguindo a metodo-
${ }^{17}$ Nesse sentido, se um país, por exemplo, diminui sua dívida externa (ou outra forma de capital externo), o seu grau de integração financeira está diminuindo. Este é precisamente o caso do Brasil a partir de 2004, já que, passado o susto da crise de confiança em 2002/2003, os agentes ficaram mais receosos de se endividarem em moeda estrangeira, em particular aqueles que não tinham receitas denominadas em dólar.

${ }^{18}$ Ver, em particular, Goldfajn e Minella (2005), van der Lann (2007) e Paula (2011). 
logia do índice IFIGDP elaborado por Lane e Milesi-Ferretti (2003). ${ }^{19}$ A Figura 2 (eixo da esquerda) mostra a evolução desse índice de 1990 a 2007. Conforme pode ser observado no gráfico, os dois índices estáo aparentemente correlacionados até o final de 2002, ainda que em 1993-1994 tenha havido um pequeno interregno restritivo. A partir de
2003, observa-se a continuidade do processo liberalização normativa, enquanto a integração financeira de facto se reduz acentuadamente, principalmente em função do pagamento de empréstimos externos, no contexto da valorização da taxa de câmbio, e da política de formaçáo de reservas cambiais das autoridades monetárias.

\section{Figura 2 - IIF e ILF para a economia brasileira - 1990/2007}

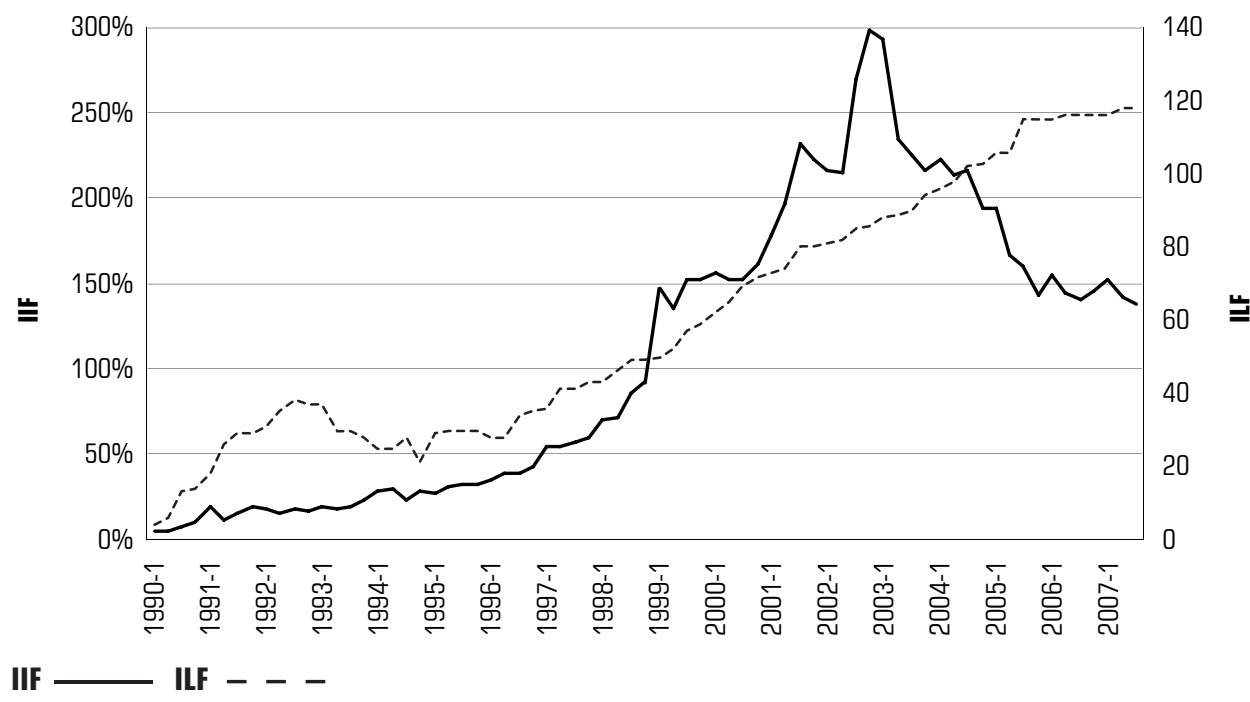

${ }_{19}$ Para o cálculo desse índice foram somados os ativos das contas Investimento brasileiro direto, Investimento brasileiro em ações, Investimento brasileiro em títulos, Derivativos, Outros

Fonte: Elaboração própria, a partir de dados do FMI (IIF), van der Laan (2007) e Banco Central do Brasil (ILF)

investimentos brasileiros,

Erros e omissóes, Haveres

da autoridade monetária; e os passivos das contas Investimento estrangeiro direto, Investimento estrangeiro em ações, Investimento estrangeiro em títulos, Derivativos, Outros investimentos estrangeiros, Operações de regularização FMI, Financiamentos excepcionais. Todos os valores foram extraídos do relatório do FMI, "International
Financial Statistics", sendo a soma dividida pelo PIB. Cabe ressaltar que os valores dessas rubricas não são apropriados em módulo, e sim pelos valores observados no balanço de pagamentos do país. 


\section{5_Avaliação dos efeitos da liberalização financeira no Brasil com o uso da metodologia VAR}

Como destacado anteriormente, o objetivo deste trabalho é analisar o impacto da liberalização financeira no Brasil sobre as variáveis macroeconômicas, de modo a testar tanto a hipótese de Arida de que a liberalização financeira resulta em redução no risco país e, consequentemente, na taxa de juros doméstica, quanto a hipótese (da literatura internacional pró-liberalização) de que a liberalização da conta capital tem impacto positivo sobre o crescimento econômico e efeito disciplinador sobre a política econômica. Para tanto, optou-se por utilizar a metodologia VAR, uma vez que esta permite avaliar como as variáveis utilizadas na análise dependem umas das outras, assim como seus respectivos choques. Nesse caso, cada variável é expressa como uma combinação linear de valores defasados de si mesma e de valores defasados de todas as outras variáveis do modelo (JONHSTON e DINARDO, 1997, p. 288). Assim, a VAR nos possibilita analisar o impacto dinâmico de distúrbios aleatórios no sistema de variáveis, fornecendo os instrumentos analíticos que nos permitem realizar a análise da interação dinâmica entre as mesmas.

Dessa forma, a fim de analisar o efeito da liberalização financeira sobre as demais variáveis dos modelos, será utilizado o instrumental analítico da função de impulso resposta, que nos mostra tanto o comportamento das variáveis em resposta a choques nos desvios-padrão dos valores correntes e futuros das variáveis do modelo, quanto a duração do efeito do choque sobre as variáveis.

\section{1_Descrição das variáveis utilizadas e testes de raiz unitária}

Como já assinalado, iremos nesta seção avaliar o efeito da liberalizaçáo da conta capital sobre um conjunto de variáveis macroeconômicas. Dessa forma, utilizaremos duas análises distintas: uma análise para o indice de jure e outra para o indice de facto. A base de dados do trabalho abrange o período do $3^{\circ}$ trimestre de 1994 ao $4^{\circ}$ trimestre de 2007, com frequência trimestral - período, portanto, posterior à implementação do Plano Real, e relativamente curto para justamente captar o período no qual se fizeram sentir, sobre a economia brasileira, os efeitos da liberalização da conta de capital e da integração financeira internacional.

Para a análise do modelo com o indice de jure de liberalização financeira (modelo ILF) serão utilizadas as seguintes variáveis: Produto Interno Bruto (PIB), Taxa de Câmbio Nominal (CAM), risco país (RP) e Taxa de Ju- 
ros (R), além do próprio indice de jure. Todos os dados foram extraídos do sítio do Ipeadata, à exceção do risco país, que foi fornecido diretamente pelo IPEA,${ }^{20}$ com periodicidade trimestral. Para a série do PIB foram utilizados os dados do PIB real - índice encadeado - dessazonalisado. Para a taxa de juros, utilizou-se a taxa Selic-Over (nominal). Já a série de volatilidade da taxa de câmbio foi construída pelos desviospadrão da média diária da taxa de câmbio comercial.

Em relação ao modelo do indice de facto de integração financeira (modelo IIF) as variáveis utilizadas foram as seguintes: Produto Interno Bruto (PIB), Taxa de Câmbio Nominal (CAM), ${ }^{21}$ Taxa de Inflação $(\text { INF })^{22}$ - medida pelo IPCA - e Taxa de Juros (R). Assim como no modelo de jure, todas as variáveis também foram ex- traídas do sítio do Ipeadata. Com o objetivo de suavizar as variaçóes das séries, todas as variáveis foram transformadas em logaritmos, à exceção das variáveis taxa de juros e taxa de inflação.

O primeiro passo da metodologia VAR é verificar se as variáveis utilizadas nos modelos de jure e de facto podem ser consideradas estacionárias. Em particular, as séries taxa de câmbio (CAM) e volatilidade cambial (VCAM) apresentam problemas de quebras estruturais ou observações aberrantes, o que pode comprometer os resultados obtidos com testes tradicionais de raiz unitária. Com efeito, a Figura 3 apresenta a evolução temporal dessas variáveis, em logaritmo, indicando em ambas a ocorrência de mudanças importantes em janeiro de 1999, por ocasião de mudança no regime cambial.

$\begin{array}{lll}{ }^{20} \text { De } 1994 \text { a } 1997 \text { os dados } & \text { Como será reportado na } & \text { risco país, por ser ela afetada } \\ \text { sobre risco país foram } & \text { nota 26, foi testado o modelo } & \text { pela redução dos controles } \\ \text { calculados utilizando o } & \text { também com a volatilidade } & \text { de capitais, segundo o } \\ \text { C-Bond (principal título de } & \text { da taxa de câmbio no lugar } & \text { argumento de Arida; já no } \\ \text { dívida externa brasileira) em } & \text { do nível da taxa de câmbio. A } & \text { modelo IIF (de facto) utilizou- } \\ \text { pontos-base sobre o título } & \text { série de volatilidade da taxa } & \text { se a taxa de inflação como } \\ \text { do Tesouro dos EUA, sendo a } & \text { de câmbio foi construída } & \text { uma proxy da estabilidade } \\ \text { série obtida através da média } & \text { pelos desvios-padrão } & \text { macroeconômica, uma vez } \\ \text { da série diária. A partir de } & \text { trimestrais da média diária da } & \text { que, segundo a literatura } \\ \text { 1998, foi utilizado diretamente } & \text { taxa câmbio comercial. } & \text { pró-liberalizaçáo, a integração } \\ \text { o EMBI+, do JP Morgan. } & \text { financeira internacional tem } \\ & \text { (de jure) é usada a variável } & \text { um efeito disciplinador sobre } \\ & & \text { a política econômica. }\end{array}$




\section{Figura 3 - Evolução da Taxa de Câmbio e da Volatilidade Cambial}
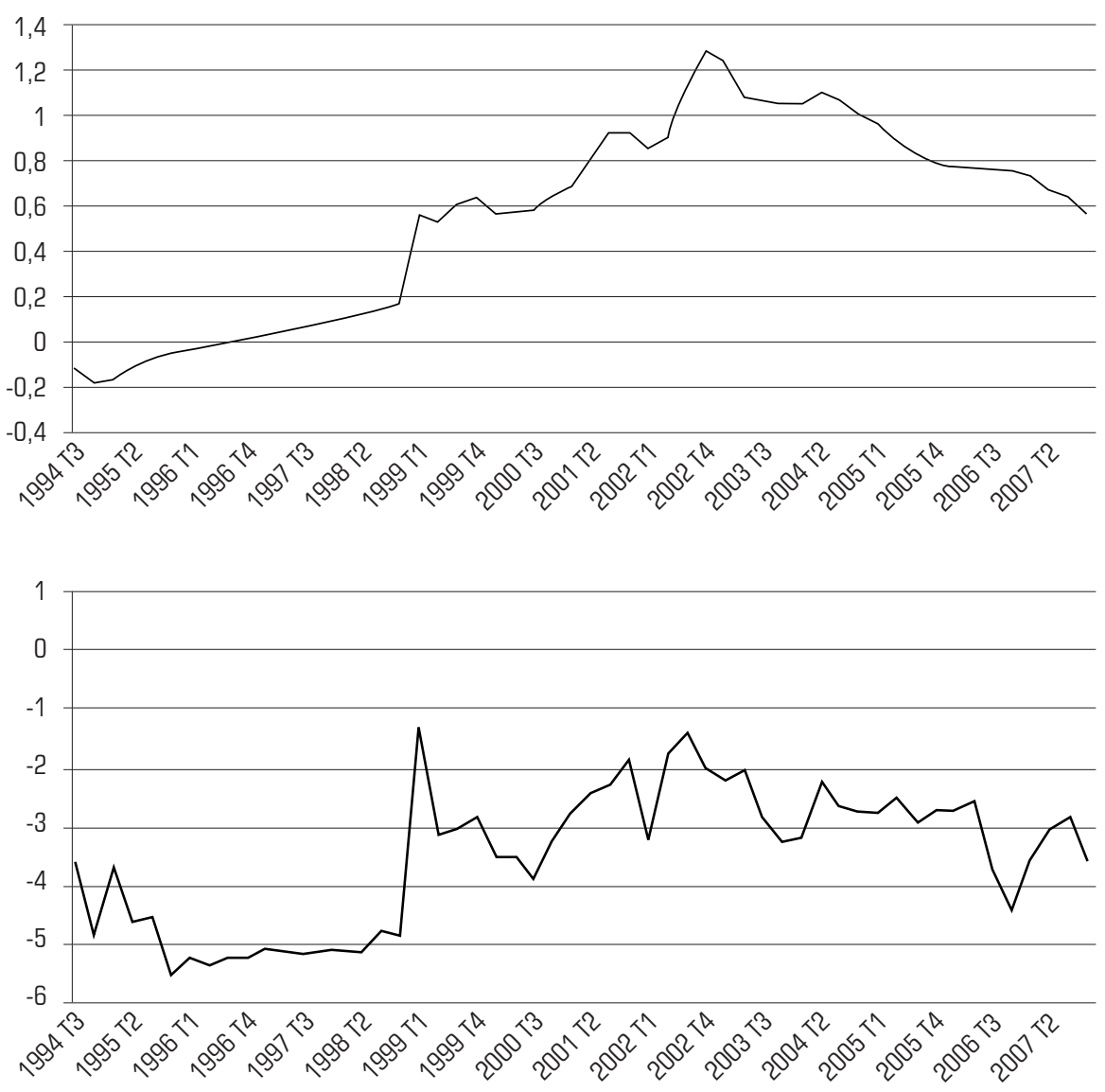

De fato, os testes ADF e KPSS para essas variáveis não geram resultados conclusivos. Assim, optou-se por utilizar o teste de Saikkonen e Lütkepohl (2002), doravante referido como SL, que modela explicitamente a quebra estrutural. Os resultados desse teste indicaram que tanto a taxa de câmbio como a volatilidade cambial possuem raiz unitária. Os testes ADF e KPSS também apresentaram resultados discrepantes para taxa de juros, reservas internacionais e risco país. Nesse caso, o teste SL também foi aplicado para definir a ordem de integração das variáveis. ${ }^{23}$
${ }^{23}$ No apêndice (Tabelas A3, A4 e A5) são apresentados os testes ADF de raiz unitária, assim como os resultados dos testes KPSS e SL. Este último foi aplicado apenas no caso em que os testes anteriores apresentaram conclusóes discrepantes. 
Tabela 1 - Testes de Raiz Unitária

\begin{tabular}{|c|c|c|c|c|}
\hline Variável & ADF & KPSS & SL & Decisão \\
\hline ILF & I (1) & I (1) & $* * *$ & I (1) \\
\hline IIF & I (1) & I (1) & $* * *$ & I (1) \\
\hline VCAM & I (1) & I $(0)$ & I (1) & I (1) \\
\hline INF & I $(0)$ & I $(0)$ & $* * *$ & I $(0)$ \\
\hline CAM & I (1) & $\mathrm{I}(0)$ & I (1) & I (1) \\
\hline PIB & I (1) & I (1) & $* * *$ & I (1) \\
\hline $\mathrm{R}$ & $\mathrm{I}(0)$ & I (1) & I (0) & I (0) \\
\hline RI & I (1) & I $(0)$ & I (1) & I (1) \\
\hline $\mathrm{RP}$ & I (1) & $\mathrm{I}(0)$ & I (1) & I (1) \\
\hline
\end{tabular}

\section{2_Apresentação dos modelos, ordenação das variáveis utilizadas e análise dos resultados}

\subsection{1_ Modelo com Índice de Liberalização Financeira (ILF)}

A formulação do modelo com o índice de liberalização financeira (ILF) tem como objetivo testar a hipótese de Arida, segundo a qual a conversibilidade plena da conta capital teria efeito de redução no risco país e, consequentemente, sobre a taxa de juros doméstica. Dessa forma, a ordenação das variáveis do modelo VAR foi feita da seguinte forma: DILF $\rightarrow$ DRP $\rightarrow$ $\mathrm{DCAM} \rightarrow \mathrm{R} \rightarrow$ DPIB. Além dessas variáveis optou-se, também, por incluir exogenamente no modelo uma variável dummy, em função da mudança de regime cambial ocorrida no início de 1999 - conforme corroborado pelos testes já mencionados anteriormente -, bem como a variável “reservas internacionais". Essa variável foi incluída como variável de controle, uma vez que, embora no período de 1994-1998, com câmbio semifixo, ela tenha funcionado como uma variável de ajuste da política econômica, na maior parte do período, 1999 a 2007, ela pode ser tratada como uma variável exógena, determinada pela política da autoridade monetária. Especificamente neste modelo (ILF), a variável "reservas internacionais" afeta paralelamente o risco país e a taxa de câmbio e, por se tratar de um modelo dinâmico, acaba por afetar, também, as demais vari- 
áveis. Cabe destacar que a inclusão dessas variáveis de controle melhorou o ajustamento dos resíduos sem alterar significativamente os resultados obtidos pela função impulso-resposta, o que revela uma maior confiança nos resultados.

Para a seleção da escolha de defasagens do modelo, utilizamos a indicação de três critérios: Akaike (AIC), Schwarz (BIC) e Hannan-Quinn (HQ). Complementarmente utilizou-se, também, a análise dos resíduos por meio dos testes de autocorrelação e de normalidade (assimetria e curtose). Dessa forma, o modelo VAR melhor ajustado apresenta uma defasagem, ainda que os testes dos resíduos não possam ser considerados satisfatórios. ${ }^{24} \mathrm{~A}$ Tabela 2 apresenta estes resultados.

Tabela 2 - Critério de defasagens e testes dos resíduos - Modelo ILF

\begin{tabular}{|c|c|c|c|c|c|c|}
\hline \multirow[t]{2}{*}{ Lags } & \multicolumn{3}{|c|}{ Critérios } & \multicolumn{3}{|c|}{ Teste dos Resíduos } \\
\hline & AIC & $\mathrm{BIC}$ & HQ & Autocorrelação & Assimetria & Curtose \\
\hline 1 & $-7.15^{*}$ & $-5.59^{*}$ & $-6.56^{*}$ & Apresenta ${ }^{\wp}$ & Apresenta & Apresenta \\
\hline 2 & -7.06 & -4.52 & -6.10 & $-\ldots-$ & -.........- & -.......-..- \\
\hline 3 & -6.95 & -3.44 & -5.62 & -...-...-..-. & -..........- & -........... \\
\hline 4 & -6.99 & -2.51 & -5.30 & -- & -..- & - \\
\hline
\end{tabular}

$\wp$ Apresenta autocorrelaçấo apenas no primeiro lag.

Após definir o modelo mais adequado, efetua-se a análise dos resultados das funçóes de impulso-resposta, como ilustrado pela Figura 4, na qual se pode observar que choques positivos na variável ILF, representados pela primeira coluna à esquerda, não produziram efeitos estatisticamente significativos sobre as variáveis macroeconômicas consideradas no mode- lo aqui utilizado. $\mathrm{O}$ único resultado significativo, além do efeito nas próprias variáveis, foi a resposta positiva da taxa de câmbio a choques do risco país, o que significa que um aumento do risco país gera um efeito de desvalorização cambial. Portanto, esses resultados (estatisticamente não significativos) sugerem a não validação da hipótese de Arida. ${ }^{25}$
${ }^{24}$ Dado que os resíduos não são bem comportados, é importante analisar a estimativa do desvio padrão do modelo a partir de métodos de simulação como o Monte Carlo. Os resultados são semelhantes aos apresentados pela Figura 4.

${ }^{25}$ Para testar a robustez dos resultados, foi realizado o mesmo exercício empírico com a troca da variável risco país pelo desvio do risco país (Brasil) em relação à média do risco país das economias emergentes (EMBI+) para o período do $3^{\circ}$ trimestre de 1998 ao $4^{\circ}$ trimestre de 2007. Os resultados da função impulso-resposta (modelo ILF 2, no Anexo) indicam que não houve mudança significativa em relação ao modelo ILF original. 
Figura 4 - Funções de Impulso Resposta - Modelo ILF

Response to Cholesky One S.D. Innovations \pm 2 S.E.
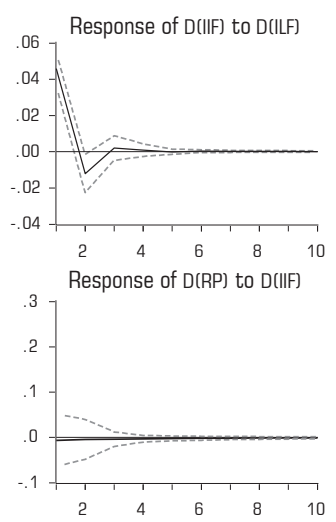

Response of D(CAM) to D(IIF)

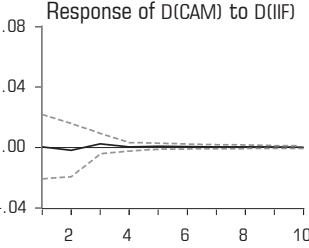

Response of D(CAM) to D(IIF)
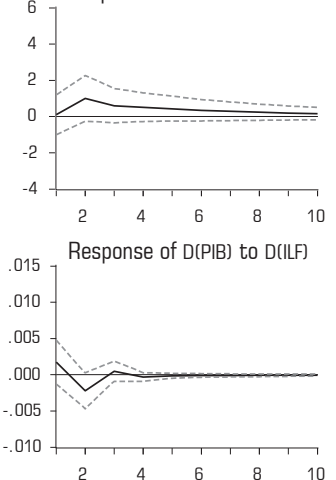
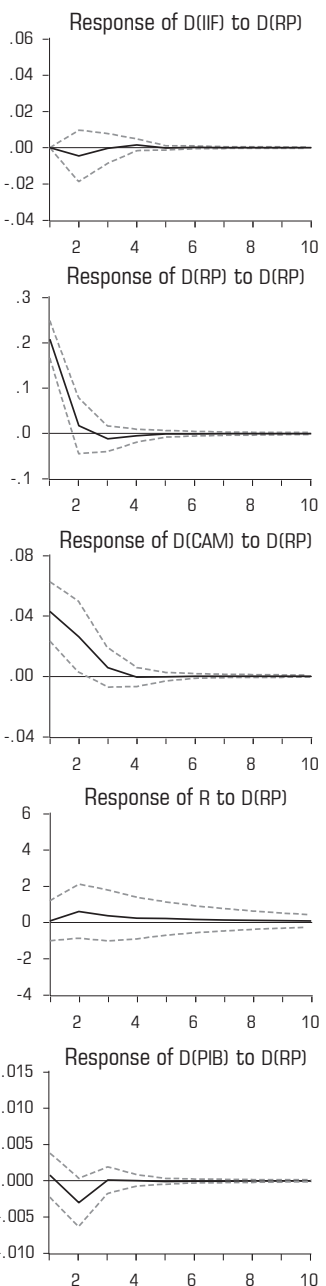
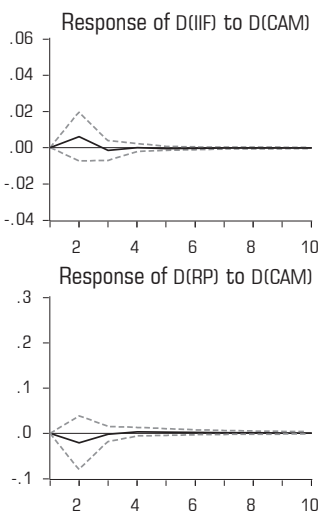

Response of D(CAM) to D(CAM)
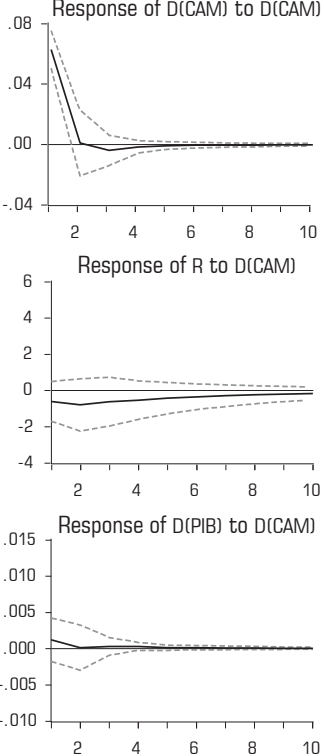
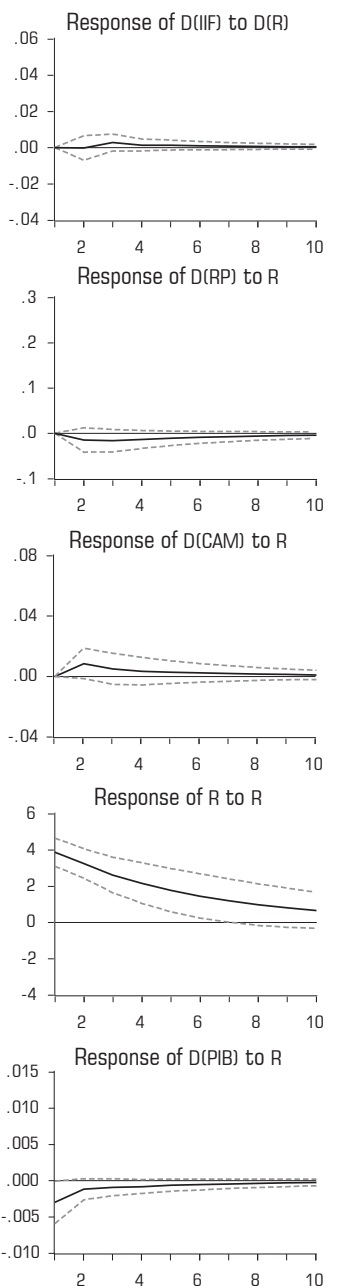
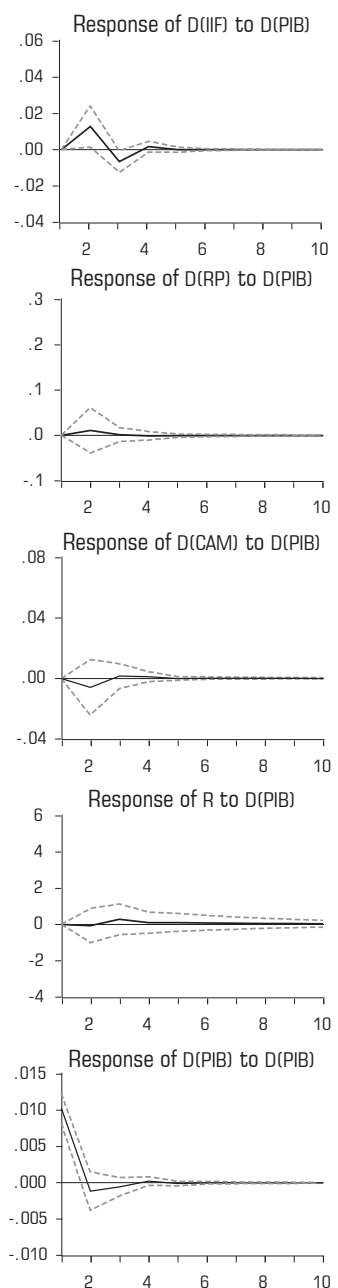


\subsection{2_ Modelo com Índice de} Integração Financeira (IIF)

O modelo com o Índice de Integração Financeira (IIF) tem como objetivo testar a hipótese da literatura internacional segundo a qual um aumento da integração financeira proporciona um efeito positivo sobre o crescimento econômico e sobre a estabilidade macroeconômica no Brasil, além de gerar efeitos disciplinadores sobre a política econômica, vis-à-vis à hipótese dos críticos da liberalização financeira de que esta gera efeitos instabilizadores em países em desenvolvimento. Assim, a ordenação das variáveis do modelo VAR IIF foi feita da seguinte forma: DIIF $\rightarrow$ $\mathrm{DCAM} \rightarrow \mathrm{INF} \rightarrow \mathrm{R} \rightarrow$ DPIB. Nesse caso, o efeito disciplinador sobre a política econômica foi testado através da resposta da taxa de inflação a choques positivos no índice de integração financeira. Assim como no modelo de jure, foram incluídas as duas variáveis de controle (dummy e reservas internacionais), que, tal como no modelo anterior, proporcionaram melhores resultados. Portanto, a ordenação reflete a ideia de que choques no índice de integração financeira impactam, em um primeiro momento, o nível da taxa de câmbio que, por sua vez, afeta a taxa de inflação; esta impacta a taxa de juros, devido principalmente à função de reação do Banco Central (via regra de Taylor), gerando, por último, efeitos sobre a taxa de crescimento do PIB.

O procedimento de escolha das defasagens do modelo foi o mesmo que no modelo de jure. Assim, escolheu-se o modelo escolhido com duas defasagens por apresentar melhor adequação dos resíduos. A Tabela 3 resume os resultados dos testes.

\section{Tabela 3 - Critério de defasagens e testes dos resíduos - Modelo IIF}

\begin{tabular}{|c|c|c|c|c|c|c|}
\hline \multirow[t]{2}{*}{ Lags } & \multicolumn{3}{|c|}{ Critérios } & \multicolumn{3}{|c|}{ Teste dos Resíduos } \\
\hline & AIC & $\mathrm{BIC}$ & HQ & Autocorrelação & Assimetria & Curtose \\
\hline 1 & -3.17 & $-1.61^{*}$ & $-2.58^{*}$ & Apresenta & Apresenta & Não apresenta \\
\hline 2 & $-3.33^{*}$ & -0.79 & -2.37 & Não apresenta & Não apresenta & Apresenta \\
\hline 3 & -3.26 & 0.24 & -1.93 & -..--.-.-- & -..-.-.-- & -........- \\
\hline 4 & -3.29 & 1.18 & -1.60 & -.........- & -.......- & -.......-- \\
\hline
\end{tabular}


As funções de impulso-resposta estão reportadas na Figura 5, na qual é indicado que um aumento da integraçáo financeira de facto gera um efeito positivo sobre a taxa de câmbio (desvalorização) e sobre a taxa de inflação, com ambos os choques se dissipando após dois trimestres. Já em relação ao PIB, um aumento na integração financeira provoca sua queda, com efeito defasado em três períodos. A resposta da taxa de juros não se apresentou estatisticamente significativa. Nos demais resultados, as respostas encontradas foram as esperadas, com a inflação e a taxa de juros respondendo positivamente a um aumento da taxa de câmbio, e com o PIB reagindo negativamente a um aumento da taxa de juros. ${ }^{26}$

Portanto, as evidências empíricas recentes mostram que o aumento da integração financeira no Brasil, além de provocar um efeito negativo sobre o PIB, ge- rou efeitos mais instabilizadores do ponto de vista macroeconômico, evidenciados pelo seu impacto de elevação na taxa de inflação e na taxa de câmbio.

\subsubsection{Evidências de Quebras Estruturais}

Com o objetivo de avaliar a estabilidade do VAR aplicou-se, ainda, o teste de Chow, elaborado por Candelon e Lütkepohl (2001), que testa a hipótese de ocorrência ou não de quebra estrutural no sistema completo de equaçóes do VAR. A hipótese alternativa do teste de Chow, em sua versão Forecast, é que todos os coeficientes, incluindo a matriz de covariância dos resíduos, podem sofrer variações. ${ }^{27}$ Devido às propriedades estatísticas em pequenas amostras poderem ser distintas das distribuiçóes assintóticas usuais $\chi^{2}$ ou F, optou-se por aplicar o referido teste por meio de simulaçóes de bootstrap. ${ }^{28}$ Além disso, em decorrência da falta de conhe-
${ }^{26}$ A fim de testar a robustez
do modelo, optamos por
testar um novo modelo,
denominado IIF2, no qual a
variável volatilidade cambial
(VCAM), em primeiras
diferenças, foi incluída no
lugar da taxa de câmbio.
Os resultados encontrados
não apresentaram mudanças significativas nas funçóes de impulso-resposta (como se pode ver no Anexo), indicando uma maior robustez do modelo.

${ }^{27}$ Existem três versóes para o teste de Chow implementadas por Candelon e Lutkepohl (2001). A primeira versáo testa a quebra nos parâmetros do
VAR (break point). A segunda versão testa a estabilidade da matriz de covariância dos resíduos (sample split). A terceira versão testa as duas possibilidades anteriores e foi utilizada por considerarse que os choques cambiais ocorridos no período pudessem gerar quebras nos parâmetros e/ou na matriz de covariância dos resíduos.

${ }^{28}$ Foram aplicadas 1.000 simulaçóes de bootstrap para cada um dos dois modelos. Alguns exercícios prévios mostraram que os resultados são insensíveis a um número maior de simulaçóes. 


\section{Figura 5 - Funções de Impulso Resposta - Modelo IIF}

Response to Cholesky One S.D. Innovations \pm 2 S.E.
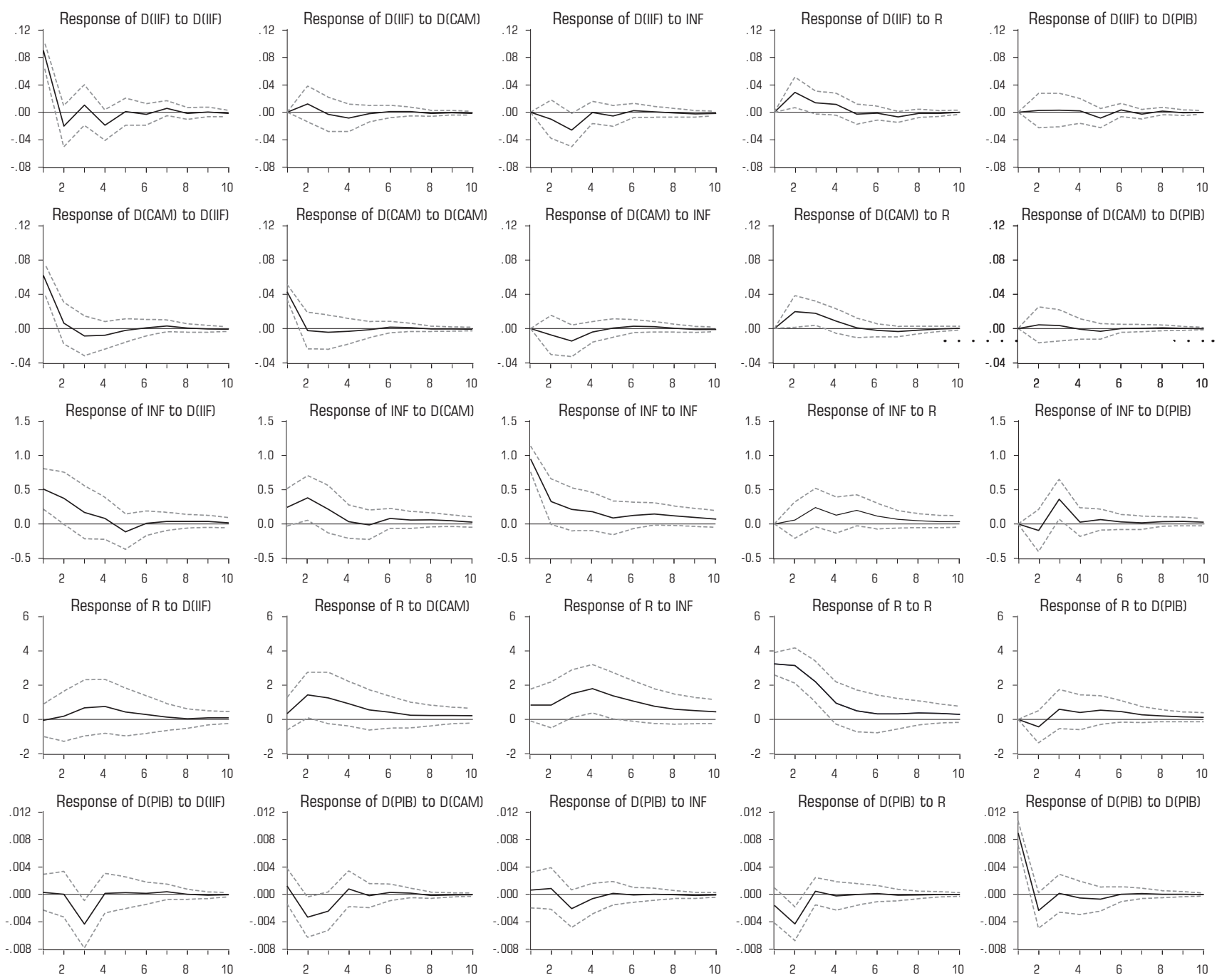
cimento prévio a respeito da data da quebra, optou-se por realizar um grid search durante o período de câmbio flutuante para que tal período pudesse ser avaliado em toda a sua extensão.

Os resultados apresentados por meio da Figura 6, que apresenta o p-valor do bootstrap do teste de Chow-Fore- cast durante o período amostral 20002007, revela que se pode rejeitar a hipótese de ocorrência de quebra estrutural no sistema VAR em ambos os modelos, já que o p-valor se situa em valores distantes dos valores críticos que configuram rejeição da hipótese nula.

Figura 6 - Teste de Quebra Estrutural de Chow - Forecast
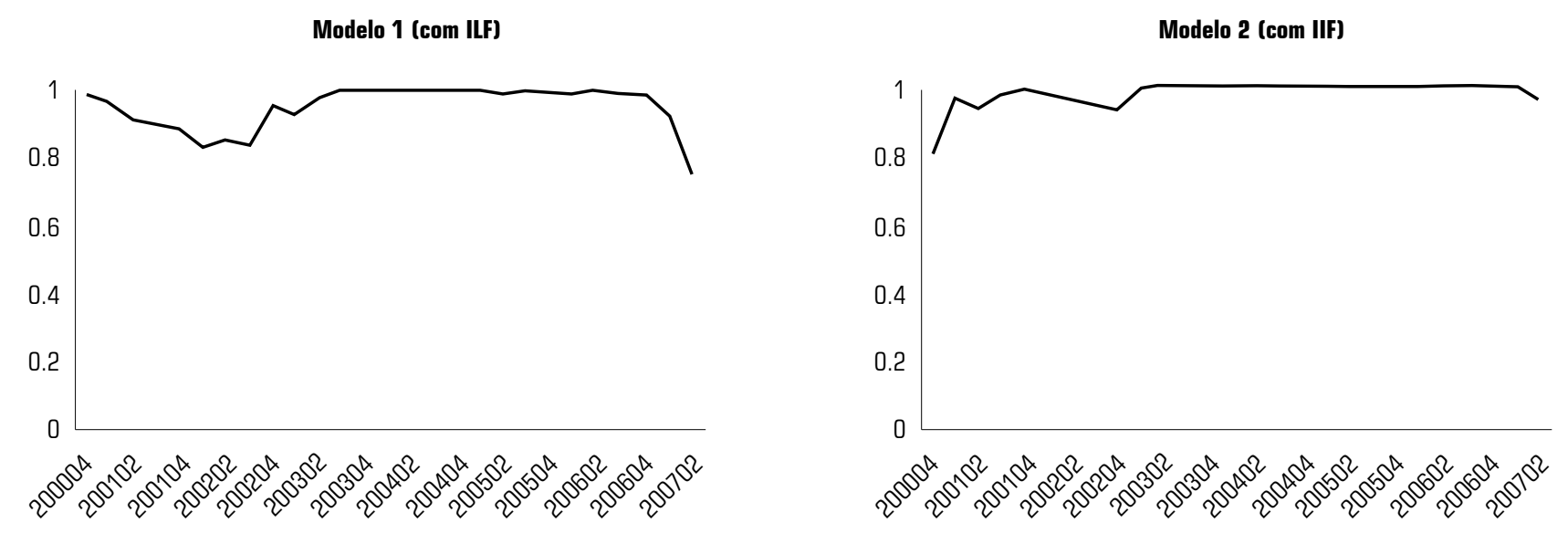


\section{6_Conclusão}

Este artigo objetivou avaliar a relação entre liberalização da conta capital, performance econômica e estabilidade macroeconômica no Brasil. Utilizando a metodologia VAR com dois modelos - um indice de jure e outro indice de facto - procurou-se avaliar, em primeiro lugar, a hipótese de Arida de que a liberalização financeira tende a reduzir o risco país e a taxa de juros doméstica, e, em seguida, de acordo com as hipóteses da literatura internacional favorável à liberalização financeira, avaliar se a desregulamentação da conta capital teve efeito positivo sobre o crescimento econômico e estabilizador do ponto de vista macroeconômico, gerando efeitos disciplinadores sobre a política econômica. Os resultados obtidos não permitem validar a hipótese de Arida, assim como não há evidências de que a liberalização financeira tenha gerado efeitos positivos sobre um conjunto de variáveis macroeconômicas. Em linha com os resultados obtidos em outros estudos da literatura internacional e nacional, os resultados alcançados neste artigo parecem dar algum suporte aos críticos da liberalização financeira, que afirmam que os efeitos instabilizadores predominam sobre os potenciais benefícios - pelo menos é isso que parece revelar o caso brasileiro recente.
Por fim, cabe ressaltar que há um amplo espectro de pesquisa sobre o tema tratado neste trabalho que pode ser explorado em outros trabalhos. Por exemplo, novos canais de transmissão da liberalização da conta capital sobre as variáveis macroeconômicas podem ser usados, como no caso dos seus efeitos sobre a taxa de investimento ou sobre o produto industrial (ao invés do PIB); efeitos da liberalização financeira considerando fluxos mais específicos, como aplicaçōes em portfólio (mercado de açóes), para aferir seu impacto sobre o grau de desenvolvimento do mercado de capitais doméstico; ou ainda, mais especificamente, o desenvolvimento de estudos numa perspectiva ao nível da firma, aferindo, entre outros, a eficiência da alocação de capital relacionada ao custo de capital das empresas. Enfim, há uma longa estrada a ser explorada. 


\section{Referências bibliográficas}

\author{
ALVES JR, A.; FERRARI- \\ FILHO, F.; PAULA, L.F. The \\ post Keynesian critique of \\ conventional currency crisis \\ models and Davidson's \\ proposal to reform the \\ international monetary system. \\ Journal of Post Keynesian \\ Economics, v. 22, n.2, p. 207-225, \\ 1999-2000.
}

ARIDA, P. Ainda a conversibilidade. Revista de Economia Politica, v. 23, n. 3, p. 135-142, 2003a

ARIDA, P. Por uma moeda plenamente conversível. Revista de Economia Politica, v. 23, n. 3, p. 151-154, 2003b.

\section{ARIDA, P. Aspectos} macroeconômicos da conversibilidade: uma discussão do caso brasileiro. Mimeo, 2004.

BHAGWATI, J. The capital myth: the difference between trade in widgets and dollar. Foreign Affairs, vol.77, n.3, p.7-12, 1998.

BELLUZZO, L.G. e CARNEIRO, R. O mito da conversibilidade. Revista de Economia Política, v. 24, n. 2, p. 218-222, 2004.

CANDELON, B.; LUTKEPOHL, H. (2001). On the reliability of Chow-type tests for parameter constancy in multivariate dynamic models. Economics

Letters, v. 73, p. 155-160, 2001.

CARDOSO, E.; GOLDFAJN,

I. Capital flows to Brazil: the endogeneity of capital controls. IMF Staff Papers, v. 45, n.1, p. 161202, 1998

CHINN, M.; ITO, H.

What matters for financial development? Capital controls, institutions and interactions. Journal of Development Economics, v.81, n.1, p. 163-192, 2006.

CUNHA, A. M. Em busca da estabilidade perdida: explorando alguns limites para o reordenamento das finanças internacionais. Econômica, v. 6, n.2, p. 223-260, 2004.

DAMASCENO, A. Integração financeira internacional e crescimento econômico: uma crítica a abordagem convencional. Economia e Sociedade, v. 16, n.2, p.171-198, 2007.

DAVIDSON, P. Financial Markets, Money and the Real World.

Cheltenham: Edward Elgar, 2002.

DORNBUSCH, R. Capital controls: an idea whose time is past. Essays in International Finance n. 207, p. 20-27, Princeton, 1998.
EATWELL, J:; TAYLOR, L. Global Finance Risk: the Case of International Regulation. New York: New Press, 2000.

EICHENGREEN, B. Capital Flows and Crises. Cambridge: The MIT Press, 2004.

EICHENGREEN, B.; LEBLANG,

D. Capital account liberalization and growth: was Mr. Mahathir right?" NBER Working Paper Series n. 9427, dezembro 2002.

EICHENGREEN, B.; GULAPALLI, R.; PANIZZA, U. Capital account liberalization, financial development and industry growth: a synthetic growth, mimeo, 2009

EDISON, H., KLEIN, M., RICCI, L.; SLOK, T. Capital account liberalization and economic performance: a survey and synthesis. NBER Working Paper Series n. 9100, agosto 2002.

EDWARDS, S. Capital mobility and economic performance: are emerging countries different? NBER Working Paper Series n. 8076, janeiro 2001.

FERRARI FILHO, F., JAYME JR, F., LIMA, G. T., OREIRO, J. L.; PAULA, L. F. Uma avaliação crítica da proposta de conversibilidade plena do real.
Revista de Economia Politica, v.25 n.1, p.133-151, 2005.

FISCHER, S. Capital account liberalization and the role of the IMF. Essays in International Finance n. 207, p. 1-10, Princeton, 1998.

GLICKMAN, M. The concept of information, intractable uncertainty, and the current state of 'efficient markets' theory: a Post Keynesian view. Journal of Post Keynesian Economics, v. 16, n.3, p. 325-349, 1994.

GOLDFAJN, I.; MINELLA, A. Capital flows and controls in Brazil: what have we learned? NBER Working Paper n.11640, setembro 2005.

GREGORY, A.; HANSEN, B. Residual-based tests for cointegration in models with regime shifts. Journal of Econometrics, v. 70, n.1, p. 99-126, 1996.

HARVEY, J. Exchange rates. In KING, J. E. (ed). The Elgar Companion to Post Keynesian Economics. Cheltenham: Edward Elgar, 2003.

HENRY, P. B. Capital account liberalization: theory, evidence, and speculation. Journal of 
Economic Literature v.45, n.4, p. 887-935, 2007.

JOHANSEN, S. Likelihood-based Inference in Cointegrated Vector Autoregressive Models. Oxford

University Press, 1995.

JOHANSEN, S., MOSCONI, R.; NIELSEN, B. Cointegration analysis in the presence of structural breaks in the deterministic trend. Econometrics Journal, v. 3, p. 216-249, 2000.

JONHSTON, J.; DINARDO, J. Econometric Methods. Singapore: McGraw-Hill, 1997.

KOSE, M., PRASAD, E., ROGOFF, K.; WEI, S-J. Financial globalization: a reappraisal. IMF Working Paper 06/189, agosto 2006 .

KRAY, A. In search of the macroeconomic effects of capital account liberalization. Mimeo, 1998.

KREGEL, J. Financial liberalization and domestic policy space: theory and practice with reference to Latin America. In ARESTIS, P. e PAULA, L. F. (org.). Financial Liberalization and Economic Performance in Emerging Countries. London: Palgrave Macmillan, 2008.

LANE, P. R.; MILESI-FERRETTI G. M. International financial integration. IMF Staff Papers, vol.50, edição especial, p. 82-113, 2003.

LANE, P. R.; MILESI-FERRETTI G. $M$. The external wealth of nations mark II: revised and extended estimatives of foreign assets and liabilities, 1970-2004. IMF Working Paper 06/69, março 2006.

MOLLO, M. L. R.; AMADO, A. M. Liberalização e financeirização das economias: a preferência pela liquidez e a necessidade de controles regulatórios. In: FERRARI FILHO, F. (Org.). Teoria Geral Setenta Anos Depois. Porto Alegre: Editora UFRGS, 2006.

OREIRO, J. L.; PAULA, L. F.; SILVA, G. J. Por uma moeda parcialmente conversível: uma crítica a Arida e Bacha. Revista de Economia Política, v. 24, n.2, p. 223-237, 2004.

ONO, F. H.; SILVA, G. J.; OREIRO, J. L.; PAULA, L. F. Taxa de juros e crescimento econômico: uma avaliação empírica da proposta de plena conversibilidade do real. Revista de Economia Contemporânea, v.9, n.2, p. 231-261, 2005.

PAULA, L. F. Financial Liberalization and Economic Performance: Brazil at the Crossroads. London:

Routledge, 2011.

PRIEWE, J. Capital account management or laissez-faire of capital flows in developing countries. In ARESTIS, P. e PAULA, L. F.(org.). Financial Liberalization and Economic Performance in Emerging Countries. London: Palgrave Macmillan, 2008.

PRASAD, E.; ROGOFF, K; WEI, S.; KOSE, M. Effects of financial globalization on developing countries: some empirical evidence. Mimeo. 2003.

QUINN, D. P. The correlates of changes in international financial regulation. American Political Science Review, n.91, p.531-551, 1997.

RESENDE, M. F. C.; AMADO, A. M. Liquidez internacional e ciclo reflexo: algumas observações para a América Latina.

Revista de Economia Política, v. 27, n.1, p.41-59, 2007.

RODRIK, D. Who needs capital-account convertibility? Essays in International Finance $\mathrm{n}$. 207, p. 55-65, Princeton, 1998.

SAIKKONEN, P.; LÜTKEPOHL, $\mathrm{H}$. Testing for a unit root in a time series with a level shift at unknown time. Econometric Theory 18: 313-348, 2002.

SINGH, A. Capital account liberalization, free long-term capital flows, financial crises and economic development. ESRC Centre for Business Research Working Paper n.245, dezembro 2002 .

STIGLITZ, J. Capital market liberalization, economic growth, and instability. World Development, v. 28 n. 6, p. 1075 1086, 2000.

VANN DER LAAN, C.R.

Liberalização da Conta de Capitais: Evolução e Evidências para o Caso Brasileiro Recente (1990-2005). Rio de Janeiro: BNDES, 2007.

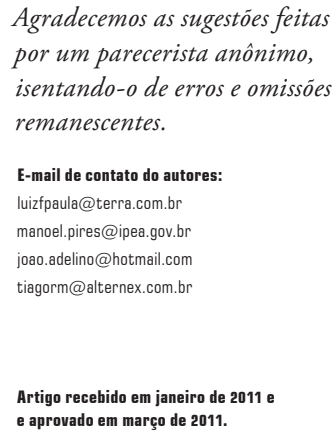




\section{Anexos}

\section{Figura A.1 - Funções de Impulso Resposta - Modelo ILF 2}

Response to Cholesky One S.D. Innovations \pm 2 S.E.
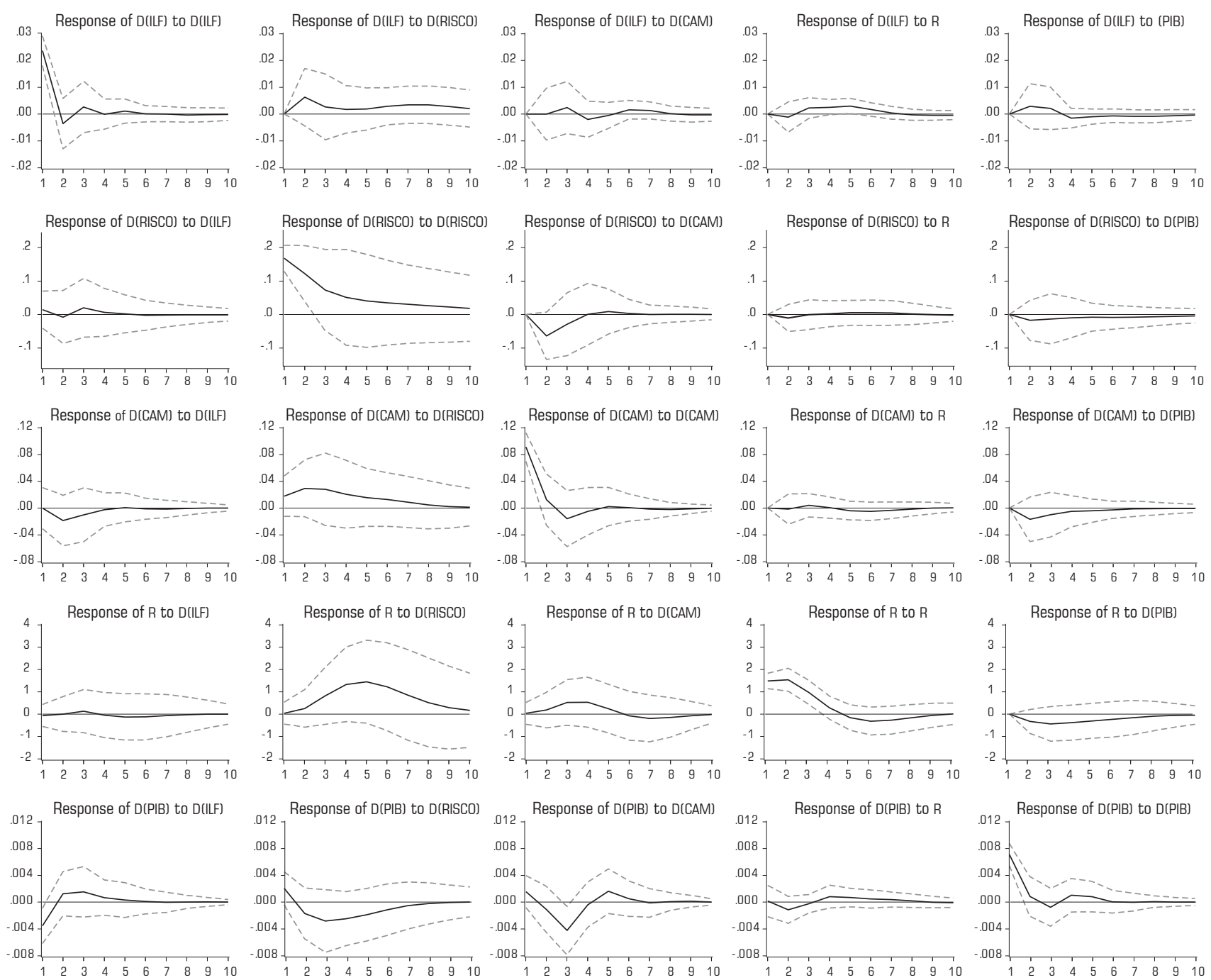


\section{Figura A.2 - Funções de Impulso Resposta - Modelo IIF 2}

Response to Cholesky One S.D. Innovations \pm 2 S.E.
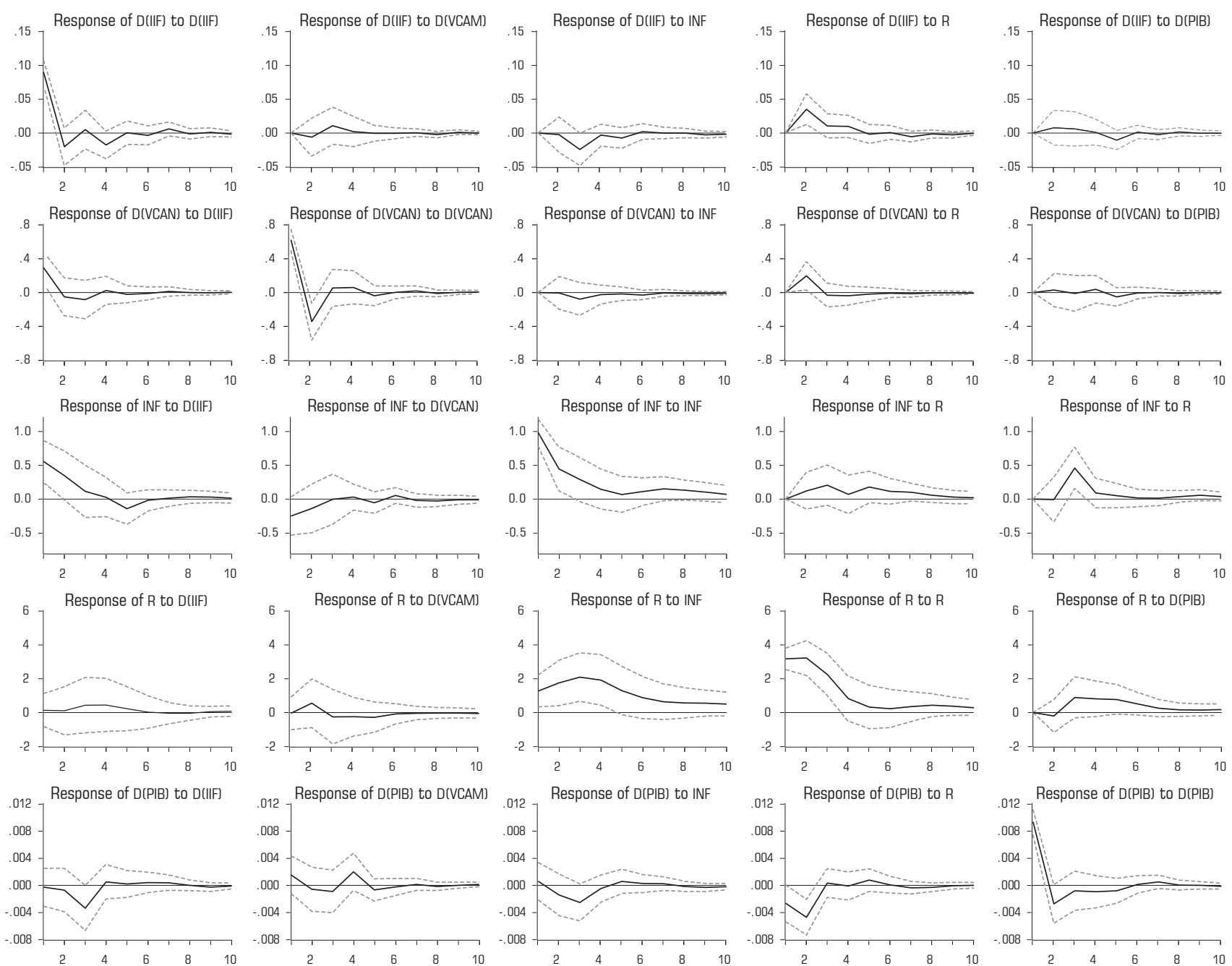
Tabela A.3 - Teste ADF

\begin{tabular}{|c|c|c|c|c|}
\hline Variável & Modelo (lags) & Estatística & $\begin{array}{c}\text { Valor } \\
\text { Crítico a } \mathbf{5 \%}\end{array}$ & P-Valor \\
\hline ILF & $c+t(1)$ & $-1,3874$ & $-3,5004$ & 0,8530 \\
\hline $\mathrm{D}$ (ILF) & $c+t(0)$ & $-14,8560$ & $-3,5004$ & 0,0000 \\
\hline IIF & $c+t(0)$ & $-0,6189$ & $-3,4986$ & 0,9736 \\
\hline $\mathrm{D}(\mathrm{IIF})$ & $c+t(4)$ & -3.6679 & $-3,5085$ & 0,0346 \\
\hline VCAM & c $(0)$ & $-2,4236$ & $-2,9187$ & 0,1404 \\
\hline D(VCAM) & $c(0)$ & $-10,5311$ & $-2,9199$ & 0,0000 \\
\hline INF & c $(0)$ & $-5,0232$ & $-2,9187$ & 0,0001 \\
\hline CAM & c $(0)$ & $-1,5794$ & $-2,9187$ & 0,4858 \\
\hline $\mathrm{D}(\mathrm{CAM})$ & c $(0)$ & $-5,6705$ & $-2,9199$ & 0,0000 \\
\hline PIB & $c+t(0)$ & $-1,4336$ & 3,4986 & 0,8391 \\
\hline $\mathrm{D}(\mathrm{PIB})$ & $c+t(0)$ & $-8,2157$ & $-3,5004$ & 0,0000 \\
\hline $\mathrm{R}$ & c (2) & $-3,3116$ & $-2,9211$ & 0,0089 \\
\hline RI & c $(0)$ & 0,9288 & $-2,9187$ & 0,9952 \\
\hline $\mathrm{D}(\mathrm{RI})$ & c $(0)$ & $-5,1993$ & $-2,9199$ & 0,0001 \\
\hline $\mathrm{RP}$ & $\mathrm{c}(0)$ & $-0,7082$ & $-2,9187$ & 0,8355 \\
\hline $\mathrm{D}(\mathrm{RP})$ & c $(0)$ & $-5,9659$ & $-2,9199$ & 0,0000 \\
\hline
\end{tabular}


Tabela A.4 - Teste KPSS

\begin{tabular}{|c|c|c|c|}
\hline Variável & Modelo & Estatística & Valor Crítico a $\mathbf{5 \%}$ \\
\hline ILF & $c+t$ & 0,2438 & 0,146 \\
\hline $\mathrm{D}$ (ILF) & c & 0,2539 & 0,463 \\
\hline IIF & $c+t$ & 0,2383 & 0,146 \\
\hline D(IIF) & $c+t$ & 0,1114 & 0,1460 \\
\hline VCAM & c & 0,1141 & 0,1460 \\
\hline INF & c & 0,3759 & 0,4630 \\
\hline CAM & c & 0,6819 & 0,4630 \\
\hline $\mathrm{D}(\mathrm{CAM})$ & c & 0,5059 & 0,4630 \\
\hline PIB & $c+t$ & 0,2291 & 0,1460 \\
\hline $\mathrm{D}(\mathrm{PIB})$ & c & 0,2815 & 0,4630 \\
\hline $\mathrm{R}$ & c & 0,6861 & 0,4630 \\
\hline RI & c & 0,3270 & 0,4630 \\
\hline $\mathrm{RP}$ & c & 0,3616 & 0,4630 \\
\hline
\end{tabular}

Tabela A.5 - Testes SL

\begin{tabular}{c|c|c|c|c} 
Variável & Quebra & Modelo (lags) & Estatística & Valor Crítico a $5 \%$ \\
\hline CAM & $1999: 1$ (dummy shift) & $\mathrm{c}(2)$ & -1.2674 & -2.88 \\
\hline VCAM & $1999: 1$ (dummy shift) & $\mathrm{c}(0)$ & -1.9546 & -2.88 \\
\hline R & $1997: 4$ (dummy shift) & $\mathrm{c}(2)$ & -6.9343 & -2.88 \\
\hline RI & $2000: 2$ (dummy shift) & $\mathrm{c}(1)$ & 0.3043 & -2.88 \\
\hline RP & $2002: 3$ (dummy shift) & $\mathrm{c}(0)$ & -0.2525 & $-2.88 \ldots \ldots$
\end{tabular}

* Para o teste KPSS a hipótese nula é de estacionariedade, enquanto para o teste SL é o contrário. 